\title{
Laboratory study of the collection efficiency of submicron aerosol particles by cloud droplets - Part II: Influence of electric charges
}

\author{
Alexis Dépée ${ }^{1,2}$, Pascal Lemaitre ${ }^{1}$, Thomas Gelain ${ }^{1}$, Marie Monier ${ }^{2,3}$, and Andrea Flossmann ${ }^{2,3}$ \\ ${ }^{1}$ Institut de Radioprotection et de Sûreté Nucléaire (IRSN), PSN-RES, SCA, Gif-sur-Yvette, 91192, France \\ ${ }^{2}$ Université Clermont Auvergne, Laboratoire de Météorologie Physique, Clermont-Ferrand, France \\ ${ }^{3}$ CNRS, INSU, UMR 6016, LaMP, Aubière, France
}

Correspondence: Pascal Lemaitre (pascal.lemaitre@ @irsn.fr)

Received: 6 August 2020 - Discussion started: 26 August 2020

Revised: 1 February 2021 - Accepted: 26 February 2021 - Published: 6 May 2021

\begin{abstract}
A new In-Cloud Aerosol Scavenging Experiment (In-CASE) has been developed to measure the collection efficiency (CE) of submicron aerosol particles by cloud droplets. Droplets fall at their terminal velocity through a $1 \mathrm{~m}$ high chamber in a laminar flow containing aerosol particles. At the bottom of the In-CASE chamber, the droplet train is separated from the aerosol particles flow, and the droplets are collected in an impaction cup, whereas aerosol particles are deposited on a high-efficiency particulate air (HEPA) filter. The collected droplets and the filter are then analysed by fluorescence spectrometry since the aerosol particles are atomised from a sodium fluorescein salt solution $\left(\mathrm{C}_{20} \mathrm{H}_{10} \mathrm{Na}_{2} \mathrm{O}_{5}\right)$. In-CASE fully controls all the parameters which affect the $\mathrm{CE}$ - the droplets and aerosol particles size distributions are monodispersed, the electric charges of droplets and aerosol particles are known and set, and the relative humidity is indirectly controlled via the chamber's temperature. This paper details the In-CASE setup and the dataset of 70 measurements obtained to study the impact of the electric charges on CE. For this purpose, droplets and particles charges are controlled through two charging systems developed in this work - both chargers are detailed below. The droplet charge varies from $-3.0 \times 10^{4} \pm 1.4 \times 10^{3}$ to $+9.6 \times 10^{4} \pm 4.3 \times 10^{3}$ elementary charges, while the particle charge ranges from zero to $-90 \pm 9$ elementary charges depending on the particle radius. A droplet radius of $48.5 \pm 1.1 \mu \mathrm{m}$ has been considered for four particle dry radii between 100 and $250 \mathrm{~nm}$ while the relative humidity level during experiments is $95.1 \pm 0.2 \%$. The measurements are then compared to theoretical models from literature - showing good agreement.
\end{abstract}

\section{Introduction}

Aerosol particles (APs) are a fundamental part of the atmosphere since they act on climate and more locally on meteorology (Twomey, 1974). They are also a key topic in human health where APs are known to increase mortality (Dockery et al., 1992). For these reasons, the processes involved in the removing of the atmospheric AP have been investigated extensively over the last decades, through theoretical works (Slinn and Hales, 1971; Beard, 1974; Slinn, 1974, 1977; Young, 1974; Grover and Beard, 1975; Grover et al., 1977; Davenport et al., 1978; Wang et al., 1978; Flossmann, 1998; Santachiara et al., 2012; Tinsley and Zhou, 2015; Cherrier et al., 2017; Dépée et al., 2019) as well as experimental measurements in the lab (Kerker and Hampl, 1974; Wang and Pruppacher, 1977; Lai et al., 1978; Barlow and Latham, 1983; Pranesha and Kamra, 1996; Vohl et al., 2007; Ladino et al., 2011; Quérel at al., 2014; Ardon-Dryer et al., 2015; Lemaitre et al., 2017; Dépée et al., 2021) and the environment (Volken and Schumann, 1993; Laasko et al., 2003; Chate and Pranesha, 2004; Depuydt, 2013; Laguionie et al., 2014). Far away from the source, APs are mainly scavenged through their collection by clouds and precipitations (Jaenicke, 1993) - referred to as the wet deposition. Since it has been reported that the AP collection by clouds is dominated by wet deposition (Flossmann, 1998; Laguionie et al., 2014), the in-cloud AP collection remains an essential issue for the atmospheric sciences.

As previously stated in Part I of this work (Dépée et al., 2021), in most of current AP wet removal models - like DESCAM (Detailed Scavenging Model, Flossmann, 1985) 
- the AP collection is described through a microphysical parameter called "collection efficiency" (CE), which quantifies the ability of a droplet to capture the APs present in its surroundings during its fall. It is the ratio between the AP number (or mass) collected by the droplet over the AP number (or mass) within the volume swept by the droplet for a given AP radius. Another equivalent definition is the ratio of the crosssectional area inside which the AP trajectories are collected by the droplet over the cross-sectional area of the droplet.

Many microphysical effects influence this CE, and their contribution is mainly dependent on the AP size. To be collected an AP has to deviate from the streamline around the falling droplet to make contact with it. The nanometric AP's trajectory is affected by the collisions with air molecules referred to as the Brownian diffusion. It results in random movement patterns (see Fig. 1a) which tend to increase the $\mathrm{CE}$ when the AP radius decreases. For massive APs, there is an increase in CE as they retain an inertia strong enough to deviate significantly from the streamline when it curves and to move straight toward the droplet surface - known as inertial impaction (see Fig. 1b). When considering intermediate AP size, the CE goes through a minimum value called the "Greenfield gap" (Greenfield, 1957) where the AP diffusion and inertia are weaker. In this gap, other microphysical effects can be involved to make the droplet encounter the AP, like the interception for instance. It is the collection of APs following a streamline that approaches the droplet within a distance equivalent to the particle radii $(a)$ - see Fig. 1c. Note that there are also thermophoretic and diffusiophoretic forces which can have an influence on the CE. These effects prevail in subsaturated air - as it is the case sometimes in clouds and are discussed in Part I (Dépée et al., 2021).

Since droplets are naturally charged in clouds (Takahashi, 1973) as well as the atmospheric APs, there are electrostatic forces which can influence the AP collection. Numerous numerical studies were dedicated to the influence of the electric charges on CE - such as Grover et al. (1975), Jaworek et al. (2002), Tinsley and his group (for instance - Tinsley et al., 2006 or Tinsley and Zhou, 2015). They suggest an increase in the CE of several orders of magnitude even when the AP is weakly charged. However, the AP charge increases when the APs are radioactive (Clement and Harrison, 1992) - inducing an impact on CE that is even larger (Dépée et al., 2019). Thus, the AP "electroscavenging" in clouds has to be investigated, particularly for nuclear safety issues when the AP removal by clouds results from the discharge of radioactive materials from a nuclear accident. For this purpose, the modelled CEs with electrostatic forces need to be experimentally validated before the incorporation in cloud models. In particular, the analytical expression for electrostatic forces used in numerical studies (Jaworek et al., 2002; Tinsley et al., 2006; Tinsley and Zhou, 2015; Dépée et al., 2019) has to be confirmed by measurements.

When a droplet with a charge $Q$ approaches an AP of charge $q$, the partial influence of the AP electrostatic field on the droplet leads to the re-orientation of the water dipoles. As a result, a surface charge distribution on the droplet is created and supposed to be comparable to the one of a conductive sphere. In an electrostatic equivalent problem, the droplet can be replaced by two point charges (Jackson, 1999) - one modelling the charge distribution, inside the droplet and near its surface, and another for the residual droplet charge located at the droplet surface. Finally, the analytical expression of the electrostatic forces is the addition of two Coulomb forces between the AP and the two-point charges inside the droplet. The factored expression can be found in Eq. (10), and further details can be found in Tinsley et al. (2000). It consists of two terms. The first one is the Coulomb inverse square term which prevails in the AP collection for large enough AP electrical mobilities or electric charge products $(q \times Q)$, attractive (Fig. 1d) or repulsive (Fig. 1e) depending on whether the AP charge $(q)$ and the droplet charge $(Q)$ have unlike or like signs. The second term is referred to as the short-range attractive term and dominates for weak electric charge products or for small AP electrical mobilities (Fig. 1f) and is always attractive (due to the charge distribution at the droplet surface with opposite sign to the AP charge). A detailed study of their contribution can be found in Tinsley and Zhou (2015) or Dépée et al. (2019).

Several laboratory studies investigated the influence of the electric charges on the CE (Beard, 1974; Wang and Pruppacher, 1977; Lai et al., 1978; Barlow and Latham, 1983; Wang et al., 1983; Byrne and Jennings, 1993; Lemaitre et al., 2020) - summarised in Table 1. However, most of these works have faced difficulties in controlling all parameters impacting the CE. For instance, Beard (1974) did not measure the AP charge; Lai et al. (1978) used a polydispersed AP size distribution - the relative humidity level was not provided, and the terminal velocity of the droplets was not reached; Barlow and Latham (1983) used a polydispersed AP size distribution, and the relative humidity level significantly varied from $50 \%$ to $70 \%$ in their measurements; in the work of Byrne and Jeannings (1993) the droplet velocity does not reach the terminal velocity; the relative humidity measured in Lemaitre et al. (2020) varied from $27 \%$ and $37 \%$. For these reasons, it is really difficult to find comparable CE measurements in the literature as Barlow and Latham (1983) concluded after highlighting a discrepancy of a few orders of magnitude between all these authors. Nevertheless, Wang and Pruppacher (1977) and Wang et al. (1983) succeeded in controlling the charges and the sizes (as well as the relative humidity for Wang and Pruppacher, 1977), but they considered only unlike signs between droplets and APs. In their study, Lemaitre et al. (2020) did not observe any influence of electric charges on $\mathrm{CE}$ since for the low relative humidity level and the large droplet radius considered, the diffusiophoresis and thermophoresis dominated the AP collection.

Thus, only the Coulomb inverse square term in the analytical expression of the electrostatic forces can be documented, 
whereas the contribution of the short-range attractive term has not been experimentally verified until now.

The purpose of this study is to overcome this lack of data by providing new $\mathrm{CE}$ measurements for weak and strong droplet and AP charges with both negative and positive charge products to quantify the effect of the short-range attractive term on the $\mathrm{CE}$ since its contribution was previously predicted by modelling (Tinsley and Zhou, 2015; Dépée et al., 2019).

Thus, a novel experiment has been designed to study the influence of electric charges on the $\mathrm{CE}$, which is presented in this paper. Note that this experiment was also used to study the influence of relative humidity, which is the objective of the companion paper: Part I (Dépée et al., 2021).

The first part of the paper describes the experimental setup. Afterwards, the methods to evaluate the $\mathrm{CE}$ and the uncertainties are detailed. Then, the measurements are presented and confronted with the prediction of Kraemer and Johnstone (1955) and the Lagrangian model of Dépée et al. (2019). Finally, this work concludes with the experimental validation of the Dépée et al. (2019) model and a necessary incorporation of the modelled CEs in cloud models, pollution models, climate models and so forth to study the electroscavenging.

\section{Experimental setup}

\subsection{Overview}

Figure 2 shows the In-Cloud Aerosol Scavenging Experiment (In-CASE) which has been built to study the influence of the electric charges on the CE. Droplets fall at their terminal velocity $\left(\approx 25 \mathrm{~cm} \mathrm{~s}^{-1}\right)$ into a chamber through an AP flow of $1.5 \mathrm{~L} \mathrm{~min}^{-1}$. The flow velocity is $1.3 \mathrm{~cm} \mathrm{~s}^{-1}$, and the AP transfer time in the collision chamber is almost $80 \mathrm{~s}$. The In-CASE chamber is subdivided into three parts - the injection head where droplets and APs are inserted, the collision chamber where droplets and APs interact with each other, and the aerodynamic separator set at the bottom's chamber impacts droplets into an impaction cup while uncollected APs pass out of the chamber toward a high-efficiency particulate air (HEPA) filter. For the latter stage, an Argon updraught assures that there are no APs that settle into the droplet impaction cup. More details on the In-CASE chamber can be found in Sect. 2.2 of Dépée et al. (2021).

APs are atomised from a sodium fluorescein salt solution $\left(\mathrm{C}_{20} \mathrm{H}_{10} \mathrm{Na}_{2} \mathrm{O}_{5}\right)$. This molecule has been used for its significant fluorescent properties, detectable at very low concentrations (down to $10^{-10} \mathrm{~g} \mathrm{~L}^{-1}$ ). Once generated, the APs flow through a diffusion dryer, and a portion of the flow is then directed into a differential mobility analyser (DMA; TSI 3080) to select APs following their electrical mobilities, whereas the overflow ends in an exhaust (black, Fig. 2). At the DMA's outlet, the AP size distribution is assumed to be monodispersed (discussed in Sect. 3.1). Thereafter, APs are electrically charged by a custom-designed field charger (Sect. 2.4). Since the optimised AP flow rate in the charger is $1.5 \mathrm{~L} \mathrm{~min}^{-1}$ and the maximum AP flow rate in the DMA was 1.2 $\mathrm{L} \mathrm{min}^{-1}$, during the experiments, a clean air flow rate is added at the charger's inlet. Before the AP injection in the InCASE chamber, the flow is humidified to ensure a high relative humidity level inside the collision chamber (Sect. 2.2). Thus, the hygroscopicity of the sodium fluorescein salt is considered during the experiments (see Sect. 3.2). Before the AP collection on the HEPA filter, the APs flow through a lowenergy X-ray neutraliser $(<9.5 \mathrm{keV}$, TSI 3088$)$ to eliminate charge accumulation on this filter, leading to AP deposition on the metallic walls of the filter holder. Note that the pipes are anti-static and connected to the ground (as well as the collision chamber) so there is no accumulation charge before the HEPA filter due to AP deposition.

Droplets are generated with a piezoelectric injector provided by Microfab (MJ-ABL-01 model) with an internal diameter of $150 \mu \mathrm{m}-$ at $25 \mathrm{~Hz}$ to prevent droplets from coalescing. The generator is set in a housing made with a $3 \mathrm{D}$ printer which is located in the injection head (Fig. 5, Right). An electrostatic inductor is also placed in the housing to charge droplets (Sect. 2.5). The droplet size is measured during experiments by optical shadowgraphy (with a strobe and a camera, brown colour in Fig. 2) through two opposite windows in the injection head. Further details can be found in Sect. 2.4 of Dépée et al. (2021), but note that the size distributions of the droplets generated by the piezoelectric injector are considered monodispersed since the droplet size dispersion is very low $(\sigma \sim 1 \%)$.

\subsection{Thermodynamic conditions in the In-CASE chamber}

Thermodynamic conditions were set as constant as possible during experiments to get comparable $\mathrm{CE}$ measurements. The pressure in the In-CASE chamber was $1 \mathrm{~atm}$ and the mean temperature for the campaign presented in this paper was $1.08 \pm 0.12^{\circ} \mathrm{C}$. As referred to in Sect. 2.2 of Dépée et al. (2021), the chamber's temperature is controlled through a cooling system which indirectly sets the relative humidity level in the chamber. Here, the temperature of the pure water in the humidifier placed before the In-CASE chamber (Fig. 2) was increased to get a mean relative humidity level in the chamber of $95.1 \pm 0.2 \%$. Note that this relative humidity level was the maximum which could be reached with In-CASE. In this way, the contribution of the thermophoretic and the diffusiophoretic effects in the CE measurements were reduced as much as possible.

\subsection{Droplet evaporation}

The droplet evaporation was theoretically evaluated through the Sect. 13.2 of Pruppacher and Klett (1997). The terminal velocity of the droplet $\left(U_{A, \infty} \approx 25 \mathrm{~cm} \mathrm{~s}^{-1}\right)$ is computed 
Table 1. Laboratory studies focused on the influence of electric charges on the CE. Charges are presented in number of elementary charges.

\begin{tabular}{|c|c|c|c|c|c|c|}
\hline \multirow[b]{2}{*}{ Study } & \multicolumn{6}{|c|}{ Parameter } \\
\hline & $\begin{array}{l}\text { Droplet radius } \\
(\mu \mathrm{m})\end{array}$ & $\begin{array}{l}\text { AP radius } \\
(\mu \mathrm{m})\end{array}$ & $\begin{array}{l}\text { Droplet charge } \\
(|e|)\end{array}$ & $\begin{array}{l}\text { AP charge } \\
(|e|)\end{array}$ & $\begin{array}{l}\text { Relative humidity } \\
(\%)\end{array}$ & $\begin{array}{l}\text { Terminal } \\
\text { velocity }\end{array}$ \\
\hline Beard (1974) & $200-425$ & $\begin{array}{l}\text { Monodisperse } \\
0.35-0.44 \pm 0.04\end{array}$ & $10^{4}-10^{6}$ & Not measured & 99 & Reached \\
\hline $\begin{array}{l}\text { Wang and Pruppacher } \\
\text { (1977) }\end{array}$ & $170-340$ & $\begin{array}{l}\text { Monodisperse } \\
0.25 \pm 0.03\end{array}$ & $10^{6}$ & $\begin{array}{l}9 \& 15 \\
\pm 2\end{array}$ & $23 \pm 2$ & Reached \\
\hline Lai et al. (1978) & $620 \& 820$ & $\begin{array}{l}\text { Polydisperse } \\
0.15-0.45\end{array}$ & $10^{7}-10^{8}$ & Not measured & $\begin{array}{l}\text { Neither controlled } \\
\text { nor measured }\end{array}$ & $\begin{array}{l}\text { Not } \\
\text { reached }\end{array}$ \\
\hline $\begin{array}{l}\text { Barlow and Latham } \\
\text { (1983) }\end{array}$ & $270-600$ & $\begin{array}{l}\text { Polydisperse } \\
0.2-1\end{array}$ & $10^{4}-10^{7}$ & Neutralised & $\begin{array}{l}\text { Uncontrolled but } \\
\text { measured } 50-70\end{array}$ & Reached \\
\hline Wang et al. (1983) & $69-250$ & $\begin{array}{l}\text { Monodisperse } \\
0.038-0.1\end{array}$ & $10^{7}-10^{8}$ & $1-13.5$ & Uncontrolled & Reached \\
\hline $\begin{array}{l}\text { Byrne and Jennings } \\
\text { (1993) }\end{array}$ & $400-500$ & $\begin{array}{l}\text { Monodisperse } \\
0.35-0.88\end{array}$ & $10^{5}-10^{8}$ & $360-750$ & 57 & $\begin{array}{l}\text { Not } \\
\text { reached }\end{array}$ \\
\hline Lemaitre et al. (2020) & 1275 & $\begin{array}{l}\text { Polydisperse } \\
0.15 \text { and } 0.25\end{array}$ & $10^{5}-10^{8}$ & $\begin{array}{l}\text { Neutralised and } \\
\text { measured }(0 \pm 0.1)\end{array}$ & $\begin{array}{l}\text { Uncontrolled but } \\
\text { measured } 27-37\end{array}$ & Reached \\
\hline
\end{tabular}
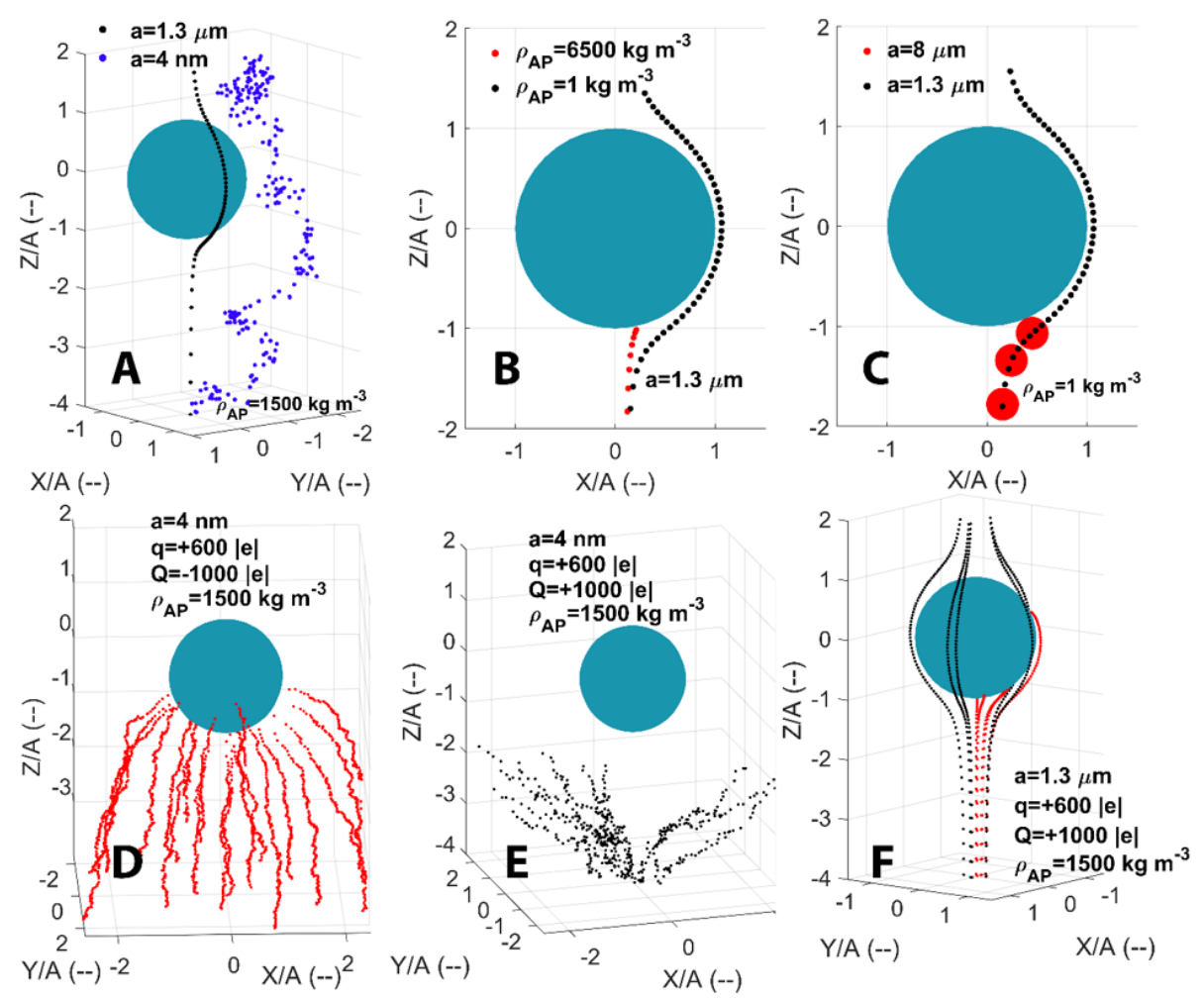

Figure 1. AP trajectories computed with the extended Dépée et al. (2019) model for a $50 \mu \mathrm{m}$ droplet radius $(A)$ and AP with various radii (a) and densities $\left(\rho_{\mathrm{AP}}\right)$. The air temperature $\left(T_{\text {air }}\right)$ and the air pressure $\left(P_{\text {air }}\right)$ are $-17^{\circ} \mathrm{C}$ and $540 \mathrm{hPa}$, respectively. The panels indicate the effects of Brownian motion (a), inertial impact (b), interception (c), and electrostatic forces with attractive (d) and repulsive (e, f) Coulomb forces. Red trajectories result in an AP collection. The droplet $(Q)$ and AP $(q)$ charges are labelled. Panels (b) to (f) - the red trajectories result in an AP collection. Adapted from Part I (Dépée et al., 2021). 


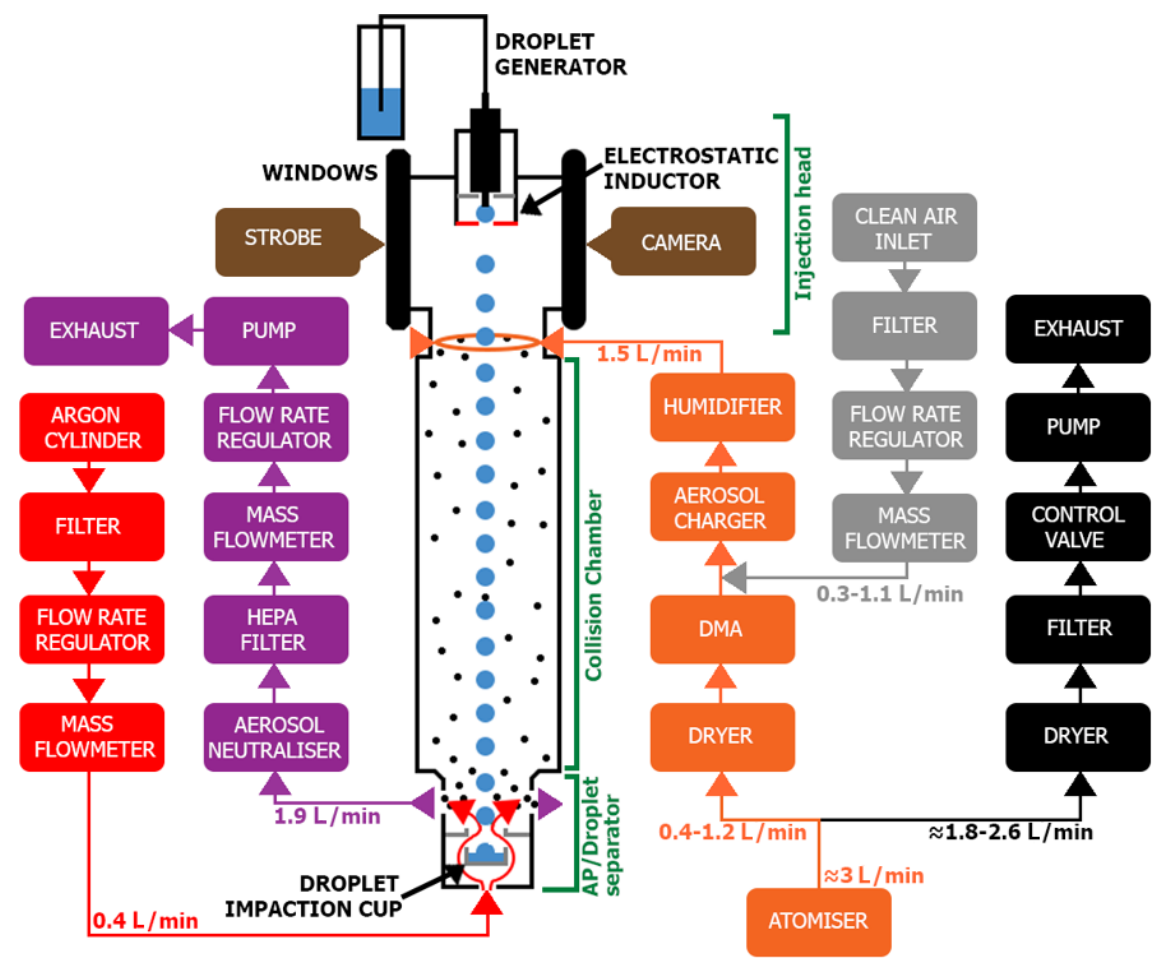

Figure 2. In-CASE setup to study the electric charges' influence - adapted from Part I (Dépée et al., 2021). Colours represent different functions. Red represents upward argon flow against AP pollution in the droplet impaction cup. Purple represents AP (and Argon) evacuation toward the HEPA filter after neutralisation. Orange represents AP, generation, selection and charging. Black represents surplus evacuation and differential mobility analyser (DMA) flow rate control. Grey represents clean air adding for a constant flow rate at the AP charger's inlet. Brown represents droplet radius measurement.

from Beard (1976), while the droplet residence time in the collision chamber $(\approx 4 \mathrm{~s})$ is deduced from the changes in droplet radius and terminal velocity. For a relative humidity level of $95 \%$, it was found that the droplet radius decreases by less than $0.3 \%$ from the droplet generation to the bottom of the collision chamber. Thus, the droplet evaporation in the In-CASE collision chamber was neglected for the discussions below.

\subsection{AP charging}

APs are electrically charged by passing through a customdesigned field charger adapted from Unger et al. (2004). The scaled geometry is presented in Fig. 3. This charger is based on a system of electric discharges produced between a highpotential tungsten wire and a grounded cylinder. A metallic converging portion is used at the charger's outlet to trap ions and ensure only charged APs can leave the charger. A Teflon ball $(\varnothing=1 \mathrm{~mm})$ is set at the end of the tungsten wire to ensure there is no point effect between the wire and the ion trap. A large number of ions are then created and migrate between the $2 \mathrm{~cm}$ interelectrode space along the electric field lines. Finally, the APs flow through them and are charged by ion attachment.
The charging relationships of the charger used during all experiments are presented in Fig. 4. They provide the mean electric AP charge related to the potential at the tungsten wire for the four AP radii considered here. It results from ex situ experiments which are detailed in Appendix A. Note that APs are negatively charged through the discharge regime used (negative Trichel regime), and there is an electric potential where the AP charge saturates, which is typical for field chargers (Pauthenier and Moreau-Hanot, 1932). These results were performed at an AP flow rate of $1.5 \mathrm{~L} \mathrm{~min}^{-1}$, which was found to maximise the AP penetration inside the charger and consequently the AP concentration inside the In-CASE chamber. Penetration tests - not presented in this study - were deduced by varying the AP flow rate in the setup detailed in Appendix A.

\subsection{Droplet charging}

The droplet charge is controlled through an electrostatic inductor adapted from Reischl et al. (1977). Two parallel metallic plates are set at the droplet generator's nozzle (Fig. 5, left) - one plate connected to the neutral potential and the other one to a potential referred to as $V_{\text {ind }}$. It induces an electric field $\left(E_{\text {ind }} \sim 10^{2}-10^{3} \mathrm{~V} \mathrm{~m}^{-1}\right)$ at the nozzle. Since sodium chloride is added to the pure water that feeds 


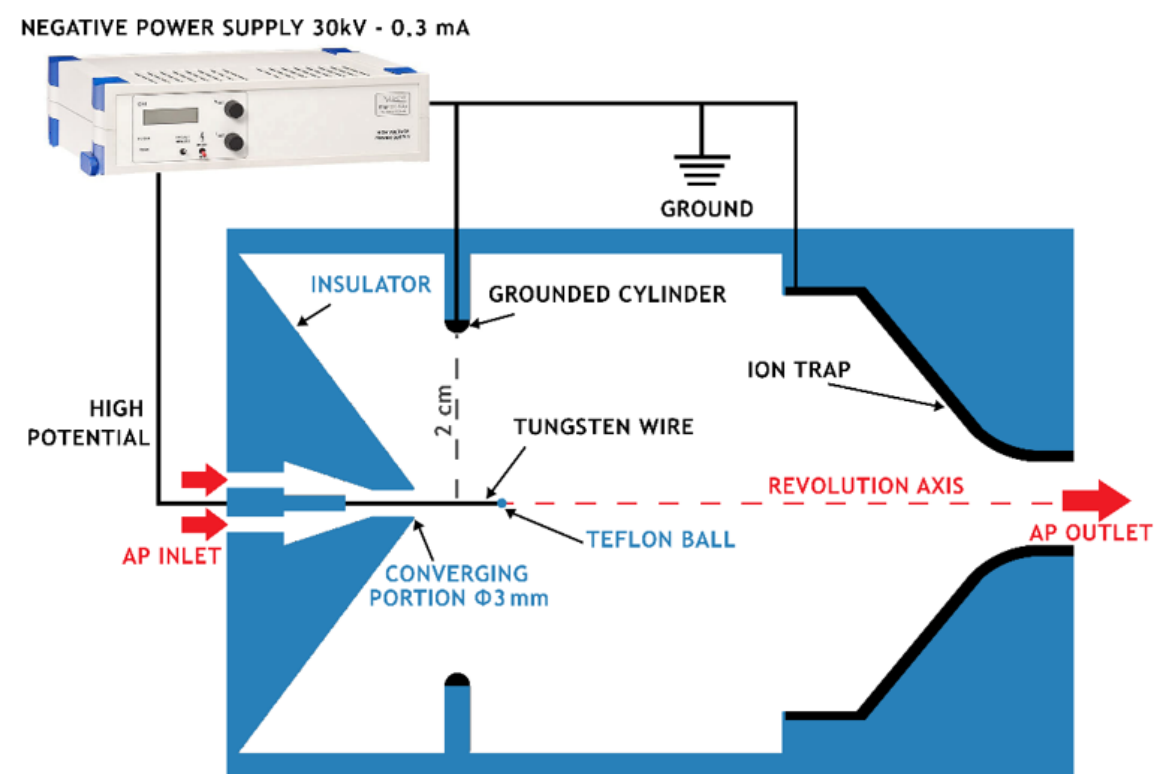

Figure 3. Geometry of the home-made AP charger based on Unger et al. (2004).

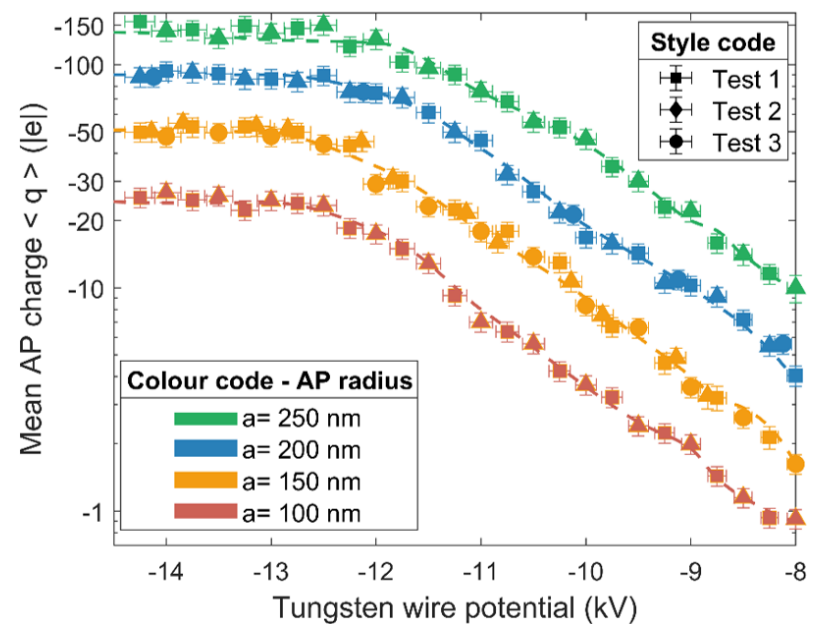

Figure 4. AP charging relationships used during experiments for the four AP radii (a) considered. Error bars represent the standard deviations in measurements.

the piezoelectric droplet generator, this electric field can selectively attract negative or positive ions toward the nozzle where the droplet is formed, according to its sign. If $V_{\text {ind }}$ is negative, the positive sodium ions $\left(\mathrm{Na}^{+}\right)$migrate toward the nozzle and the negative chloride ions $\left(\mathrm{Cl}^{-}\right)$are repulsed from the nozzle and inversely if the potential is positive. Furthermore, the amplitude of the electric field $\left(E_{\text {ind }}\right)$ sets the ion quantity in the droplet. Note that the sodium chloride concentration has no impact on the induced droplet charge if the ion number is large enough for the entire experiment time (Reischl et al., 1977) - 3.3 $\mathrm{g} \mathrm{L}^{-1}$ was used here.

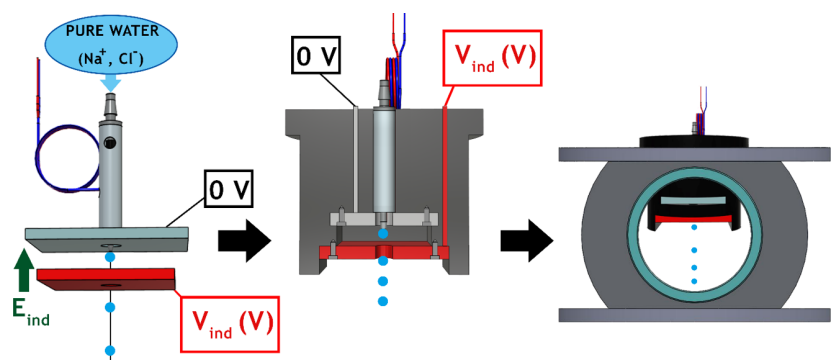

Figure 5. (Left) Electrostatic inductor below the piezoelectric droplet generator. (Centre) Cross section of the housing made with a 3D printer that holds the droplet generator. (Right) Injection head at the top of the In-CASE chamber containing the housing made with a $3 \mathrm{D}$ printer.

A method to evaluate the droplet charge was developed in this study and is detailed in Appendix B. In Fig. 6, the resulting charging relationship of the electrostatic inductor is presented. It gives the droplet charge $(Q)$ as a function of the electrostatic inductor potential $\left(V_{\text {ind }}\right)$. We note that the droplet generator produces highly electrically charged droplets since the droplet charge is evaluated to about -8400 elementary charges, for a zero potential at the inductor plate $\left(V_{\text {ind }}=0 \mathrm{~V}\right)$. This is in line with Ardon-Dryer et al. (2015), which used a similar generator and measured up to $10^{4} \mathrm{el}-$ ementary charges on the generated droplets. Finally, this charging relationship is used during experiments to positively or negatively set the droplet charges. The electrostatic inductor and the droplet generator are placed into a housing made with a 3D printer (Fig. 5, centre), with the latter being placed in the injection head at the top of the In-CASE chamber (Fig. 5, right). 


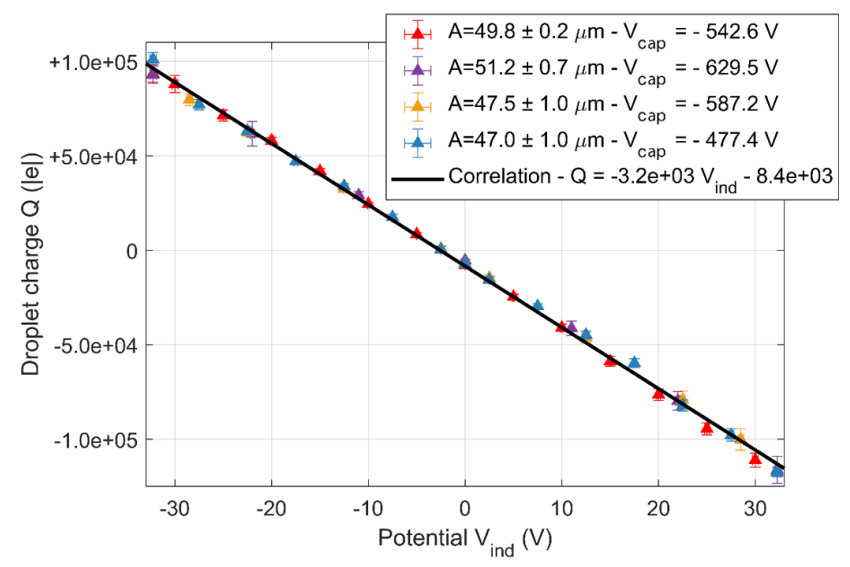

Figure 6. Droplet charge versus electrostatic inductor voltage. The colours identify different tests performed to ensure there is no droplet charge modification over time and manipulations. Error bars represent the standard deviation of the droplet radii evaluated. The parameter $V_{\text {cap }}$ is the potential at the capacitor to measure the droplet charge. Note that the radius of the droplet is deduced from the reversed Beard (1976) model and its terminal velocity - with the latter being measured by optical shadowgraphy. See Appendix B for more further details.

\section{Data analysis}

\subsection{Assumption of a monodispersed AP size distribution}

As a reminder, APs flow through a DMA (Fig. 2) to select APs following their electrical mobility. As explained in Sect. 3.2 of Part I (Dépée et al., 2021), several AP radii can actually be selected depending on their elementary charges given that they have the same electrical mobility. For example, with a selected AP radius of $100 \mathrm{~nm}$ at the DMA (considering one elementary charge on it), the doubly charged AP radii of $161.8 \mathrm{~nm}$ will also be selected.

Sometimes, the multiple charged APs cannot be neglected in the AP flow at the DMA's outlet. The CE deduction is then more difficult (Dépée et al., 2021). Here, the aerodynamic impactor at the DMA's inlet and the AP flow rate in the DMA were optimised to prevent double (and greater) charged AP from being selected by the DMA. Indeed, the cut-off radius of the impactor at the DMA's inlet (referred to as $D_{50 \% / 2}$ ) - which is the radius where $50 \%$ of the APs are impacted - is small enough compared to the double charged AP radius. This is summarised in Table 2 for all selected AP radii used in the experiments. Thus, the AP size distribution at the DMA's outlet is assumed to be monodispersed, and the CE is deduced as follows.

\subsection{Collection efficiency definition}

The collection efficiency (CE) is calculated from Eq. (1):

$\mathrm{CE}(a, A, q, Q, \mathrm{HR})=\frac{m_{\mathrm{AP}, \mathrm{d}}}{m_{\mathrm{AP}, \text { available }}}$,

where $m_{\mathrm{AP}, \mathrm{d}}$ is the AP mass collected by all droplets which is directly measured by fluorescence spectrometry analysis of the droplets collected in the impaction cup, which is located at the bottom of the In-CASE chamber (Fig. 4 of Dépée et al., 2021). $m_{\mathrm{AP} \text {,available }}$ is the mass of available APs in the volume swept by all droplets - evaluated with Eq. (2):

$m_{\mathrm{AP}, \text { available }}=\pi(A+\mathrm{GroF}(\mathrm{RH}) \times a)^{2} \times F_{\mathrm{d}} \times \Delta t$

$\times H_{\text {eff }} \times C_{\mathrm{m}, \mathrm{AP}}$,

with $A$ the droplet radius, $F_{\mathrm{d}}$ the droplet generation frequency, $\Delta t$ the experiment duration (from 3 to $6 \mathrm{~h}$ ), $a$ the AP dry radius, $C_{\mathrm{m}, \mathrm{AP}}$ the mean AP mass concentration in the In-CASE collision chamber, and GroF the growth factor of AP depending on the relative humidity (RH). The latter characterises the hygroscopicity of the sodium fluorescein salt - further details related to its evaluation can be found in Sect. 2.2.3 of Dépée et al. (2021). $H_{\text {eff }}$ is the effective height of interaction between APs and droplets calculated with Eq. (3):

$H_{\text {eff }}=\frac{U_{A, \infty}}{U_{A, \infty}+V_{Q}} H_{\text {In-CASE }}$,

with the AP flow velocity $\left(V_{Q}\right)$ equal to $1.3 \mathrm{~cm} \mathrm{~s}^{-1}$ (for an AP flow rate of $1.5 \mathrm{~L} \mathrm{~min}^{-1}$ ), the droplet terminal velocity $\left(U_{A, \infty}\right)$ assumed to be equal to $25 \mathrm{~cm} \mathrm{~s}^{-1}$ and the In-CASE collision chamber's height ( $\left.H_{\text {In-CASE }}\right)$ equal to $1 \mathrm{~m}$.

In Eq. (2), the mean AP mass concentration $\left(C_{\mathrm{m}, \mathrm{AP}}\right)$ in the In-CASE collision chamber is evaluated from the fluorescence spectrometry analysis of the HEPA filter. It is given by Eq. (4), where $Q_{\text {In-CASE,c }}$ is the AP flow rate going through the In-CASE collision chamber and $m_{\mathrm{AP} \text {,tot }}$ is the total AP mass on the HEPA filter at the end of the experiment.

$C_{\mathrm{m}, \mathrm{AP}}=\left(1+\frac{1-P_{\mathrm{In}-\mathrm{CASE}, a, q}}{2}\right) \frac{m_{\mathrm{AP}, \mathrm{tot}}}{\Delta t \times Q_{\mathrm{In}-\mathrm{CASE}, \mathrm{c}}}$

The mean AP mass concentration is corrected considering the penetration $\left(P_{\mathrm{In}-\mathrm{CASE}, a, q}\right)$ in the collision chamber which depends on the AP radius $(a)$ and charge $(q)$. This parameter was estimated during ex situ experiments where the setup was the same as Fig. 2, the only difference being a condensation particle counter (CPC) positioned behind the AP neutraliser and the AP charger to measure two AP number concentrations, $n_{1}$ and $n_{2}$, respectively. The penetration is then defined as concentration $n_{1}$ over concentration $n_{2}$. Thus, the measured penetration accounts for the AP deposition due to electrostatic forces on the wall of the collision chamber as 
Table 2. AP selection parameters.

\begin{tabular}{lrrr}
\hline $\begin{array}{l}\text { Selected dry AP } \\
\text { radius by the DMA } \\
\text { (single charged) }\end{array}$ & $\begin{array}{r}\text { Double charged } \\
\text { dry AP radius } \\
\text { with the same } \\
\text { electrical mobility }\end{array}$ & $\begin{array}{r}\text { AP flow rate in } \\
\text { the DMA }\end{array}$ & $\begin{array}{r}\text { Cut-off radius of the } \\
\text { impactor at the } \\
\text { DMA's inlet } \\
\left(D_{50 \% / 2)}\right.\end{array}$ \\
\hline $100 \mathrm{~nm}$ & $161.8 \mathrm{~nm}$ & $1.2 \mathrm{~L} \mathrm{~min}^{-1}$ & $140 \mathrm{~nm}$ \\
$150 \mathrm{~nm}$ & $253.7 \mathrm{~nm}$ & $1.0 \mathrm{~L} \mathrm{~min}^{-1}$ & $157 \mathrm{~nm}$ \\
$200 \mathrm{~nm}$ & $348.3 \mathrm{~nm}$ & $0.6 \mathrm{~L} \mathrm{~min}^{-1}$ & $213 \mathrm{~nm}$ \\
$250 \mathrm{~nm}$ & $444.3 \mathrm{~nm}$ & $0.4 \mathrm{~L} \mathrm{~min}^{-1}$ & $268.5 \mathrm{~nm}$ \\
\hline
\end{tabular}

Table 3. Measured penetration for the experimental conditions.

\begin{tabular}{lrr}
\hline $\begin{array}{l}\text { Dry AP } \\
\text { radius }(a)\end{array}$ & $\begin{array}{r}\text { AP charge } \\
(q)\end{array}$ & $\begin{array}{r}\text { Penetration } \\
\left(P_{\text {In-CASE, } a, q)}\right.\end{array}$ \\
\hline $100 \mathrm{~nm}$ & $-10 \pm 1|e|$ & $94.7 \%$ \\
& $-20 \pm 2|e|$ & $86.0 \%$ \\
\hline \multirow{2}{*}{$150 \mathrm{~nm}$} & $-11 \pm 1|e|$ & $96.5 \%$ \\
& $-30 \pm 3|e|$ & $86.2 \%$ \\
\hline $200 \mathrm{~nm}$ & $-10 \pm 1|e|$ & $97.0 \%$ \\
& $-34 \pm 3|e|$ & $88.8 \%$ \\
& $-71 \pm 7|e|$ & $78.2 \%$ \\
\hline $250 \mathrm{~nm}$ & $-22 \pm 2|e|$ & $94.1 \%$ \\
& $-52 \pm 5|e|$ & $89.6 \%$ \\
& $-90 \pm 9|e|$ & $81.8 \%$ \\
\hline
\end{tabular}

well as in the pipes from the AP charger to the HEPA filter and the humidifier (Fig. 2). The measured penetrations are presented in Table 3. It is observed that the penetration decreases when the AP charges $(q)$ increase and the AP radius (a) decreases since the electrical mobility of APs is larger. During experiments, the AP number concentration ranged from $3 \times 10^{4} \mathrm{~cm}^{-3}$ (for $a=100 \mathrm{~nm}$ and $=-10 \pm 1|e|$ ) to $2 \times 10^{3} \mathrm{~cm}^{-3}$ (for $a=250 \mathrm{~nm}$ and $q=-90 \pm 9|e|$ ). As a reminder, the pipes are anti-static and connected to the ground (as well as the collision chamber) so there is no charge accumulation due to AP deposition during experiments. Thus, the penetrations presented in Table 3 are assumed to be constant over time. Note that the AP deposition was neglected in Part I (Dépée et al., 2021) since the penetration was almost $100 \%$ when the APs are neutralised.

\subsection{Uncertainties}

The relative CE uncertainty $\left(u_{\mathrm{CE}}\right)$ is calculated following Lira (2002) and presented in Eq. (5):

$u_{\mathrm{CE}}=\sqrt{u_{A}^{2}+u_{H_{\mathrm{eff}}}^{2}+u_{N_{\mathrm{d}}}^{2}+u_{m_{\mathrm{AP}, \mathrm{d}}}^{2}+u_{C_{\mathrm{m}, \mathrm{AP}}}^{2}}$,

where the relative uncertainties are related to the droplet radius $\left(u_{A} \approx 1 \%\right)$, the effective height of interaction between droplets and APs $\left(u_{H_{\text {eff }}} \approx 4 \%\right)$, the number of injected droplets during the experiment $\left(u_{N_{\mathrm{d}}} \approx 2 \%\right)$, the measured AP mass in the droplet impaction cup $\left(u_{m_{\mathrm{AP}, \mathrm{d}}}\right)$, and the mean AP mass concentration in the In-CASE collision chamber during the experiment $\left(u_{C_{\mathrm{m}, \mathrm{AP}}}\right)$.

The relative uncertainty $u_{m_{\mathrm{AP}, \mathrm{d}}}$ is evaluated through Eq. (6):

$u_{m_{\mathrm{AP}, \mathrm{d}}}=\sqrt{u_{\text {fluorimeter }}^{2}+u_{\text {dilution }}^{2}}$,

where $u_{\text {dilution }}$ is the relative uncertainty of the dilution performed during the spectrometry analysis, assumed to be

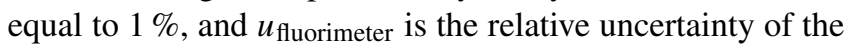
fluorimeter, which can be up to $30 \%$ when the measured AP mass is close to the detection limit. The relative uncertainty of the mean AP mass concentration in the In-CASE collision chamber $\left(u_{C_{\mathrm{m}, \mathrm{AP}}}\right)$ is calculated through Eq. (7):

$$
\begin{aligned}
u_{C_{\mathrm{m}, \mathrm{AP}}} & =\sqrt{u_{m_{\mathrm{AP}, \mathrm{tot}}}^{2}+u_{Q_{\mathrm{In}-\mathrm{CASE}, \mathrm{c}}^{2}}+u_{\Delta t}^{2}+u_{P}^{2}} \\
& \approx \sqrt{u_{m_{\mathrm{AP}, \mathrm{tot}}}^{2}+u_{Q_{\mathrm{In}-\mathrm{CASE}, \mathrm{c}}}^{2}+u_{P}^{2}}, \\
u_{m_{\mathrm{AP}, \mathrm{tot}}} & =\sqrt{u_{\text {fluorimeter }}^{2}+u_{\mathrm{dilution}}^{2}} u_{m_{\mathrm{AP}, \mathrm{tot}}} .
\end{aligned}
$$

$u_{m_{\mathrm{AP}, \text { tot }}}$ is the relative uncertainty of the measured AP mass on the HEPA filter, which depends on the relative uncertainties of the dilution $\left(u_{\text {dilution }} \approx 1 \%\right)$ and the fluorimeter $\left(u_{\text {fluorimeter }} \leq 30 \%\right)-u_{Q_{\mathrm{In}-\mathrm{CASE}, \mathrm{c}}}$ is the relative uncertainty of the AP flow rate in the collision chamber equal to $1 \%$, and $u_{\Delta t}$ is the relative uncertainty of the experiment duration which is neglected here. More details are addressed in Part I, Sect. 3.3 (Dépée et al., 2021), where the same definitions are used, except the relative uncertainty of the AP penetration in the collision chamber $\left(u_{\mathrm{P}}\right)$ is added here (Eq. 8).

$u_{\mathrm{P}}=\frac{1-P_{\mathrm{In}-\mathrm{CASE}, a, q}}{2}$

As mentioned in Sect. 4.2.3 ("Dépée et al. (2019) extended model"), an AP pollution independent from the experiment (pollution during the spectrometry analysis, when the droplet impaction cup is extracted at the end of experiments, etc.) remains and should be considered in Eq. (5). Indeed, it can significantly increase the CE measurement, especially when the measured AP mass is close to the detection limit of the 
fluorescence spectrometer. Considering the experiment duration $(<6 \mathrm{~h})$, this pollution is not totally negligible for CEs below $1 \times 10^{-4}$. Rather than discarding these measurements, there low uncertainty were extended down to the lower limit of the axis in Figs. 7 and 10.

Also, we assume that APs have the same charge $(q)$. Even if an AP charge distribution exists, this contribution is negligible. Nevertheless, the AP charge distribution was not measured here.

\section{Results and discussions}

\subsection{Extension of the Dépée et al. (2019) model}

CE measurements are compared to the model of Dépée et al. (2019), which models the electrostatic forces $\left(\boldsymbol{F}_{\text {elec }}\right)$ between droplets and APs in the CE calculation. Since all experiments were performed in subsaturated air $(\mathrm{RH}=95.1 \pm$ $0.2 \%)$, the thermophoretic $\left(\boldsymbol{F}_{\text {th }}\right)$ and the diffusiophoretic $\left(\boldsymbol{F}_{\mathrm{df}}\right)$ forces were also considered for the comparison with the model. Indeed, Dépée et al. (2021) showed that the contribution of these two effects is significant even though the relative humidity is close to $100 \%$. Thus, the Dépée et al. (2019) model is extended here by replacing the resulting velocity at the AP location $\left(\boldsymbol{U}_{\boldsymbol{f} @ \boldsymbol{a} \boldsymbol{p}}^{*}\right.$ in their Eq. 6) by Eq. (9):

$\boldsymbol{U}_{\boldsymbol{f} @ \mathrm{AP}} *(t)=\boldsymbol{U}_{\boldsymbol{f} @ \mathrm{AP}}(t)+\frac{\tau_{\mathrm{AP}}}{m_{\mathrm{AP}}}\left(\boldsymbol{F}_{\text {buoy }}+\boldsymbol{F}_{\text {df }}+\boldsymbol{F}_{\text {elec }}+\boldsymbol{F}_{\text {th }}\right)$,

where $\boldsymbol{U}_{\boldsymbol{f}} @ \mathrm{AP}$ is the fluid velocity at the AP location, $\tau_{\mathrm{AP}}$ the AP relaxation time and $m_{\mathrm{AP}}$ the AP mass. The expression of the buoyancy force $\left(\boldsymbol{F}_{\text {buoy }}\right)$ is detailed in Eq. (B1), and $\boldsymbol{F}_{\mathrm{df}}$ and $\boldsymbol{F}_{\text {th }}$ are detailed in Eq. (12) of Dépée et al. (2021). $\boldsymbol{F}_{\text {elec }}$ is defined in Eq. (10):

$$
\begin{aligned}
& \boldsymbol{F}_{\text {elec }}=\frac{q^{2}}{4 \pi \varepsilon_{0} A^{2}} \\
& {[\overbrace{\left(-\frac{r^{*}}{\left(r^{* 2}-1\right)^{2}}+\frac{1}{r^{* 3}}\right)}^{\text {Short-range attractive term }}+\underbrace{\frac{1}{r^{* 2}} \times \frac{Q}{q}}_{\text {Coulomb inverse square term }}] \boldsymbol{u}_{\mathrm{r}},}
\end{aligned}
$$

with $\varepsilon_{0}$ the permittivity of the free space, $\boldsymbol{u}_{\mathrm{r}}$ the unit vector in the radial direction from the droplet centre to the AP centre, and $r^{*}$ the distance between the AP and droplet centres, normalised by the droplet radius $A$.

Note that radioactive APs are known to get positively charged (Clement and Harrison, 1992), whereas the APs were negatively charged in this work (Fig. 4), through the charging regime used in the AP charger (for integrity of the tungsten wire over time). Nevertheless, since we have the relation $\boldsymbol{F}_{\text {elec }}(q,-Q)=\boldsymbol{F}_{\text {elec }}(-q, Q)$ in Eq. (10), the CE measurements with the same $\frac{q}{Q}$ ratios are equivalent, assum- ing this analytical expression is validated by the measurements (see Sect. 4.2.3).

\subsection{Collection efficiency measurements}

The CE measurements for various charges are presented in Table 4 for the four wet AP radii $\left(a_{\text {wet }}\right)$ considered in this study. Note that the wet AP radii are the ones of the APs which grew in the collision chamber due to their hygroscopicity. During experiments, the AP radius increases by a growth factor (GroF) between 1.73 and 1.75 (since we actually considered the four mean levels of relative humidity for the four AP radii used in the experiments). Further details related to the calculation of the growth factor can be found in Sect. 2.2.3 of Dépée et al. (2021). In Table 4, the droplet $(Q)$ and $\operatorname{AP}(q)$ charges are also informed by number of elementary charges. The mean temperature was $1.08 \pm 0.12^{\circ} \mathrm{C}$, and the mean relative humidity was $95.1 \pm 0.2 \%$, for a droplet radius of $48.5 \pm 1.1 \mu \mathrm{m}$. Note that the wet AP density depends on the one of sodium fluorescein salt and water. Equation (1) of Dépée et al. (2021) yielded a density of $1110 \mathrm{~kg} \mathrm{~m}^{-3}$. The key features of the experiments are summarised in Table 5 .

\subsubsection{Effect of the product of the droplet and AP charges on the collection efficiency}

The CE measurements for a wet AP radius of $432 \mathrm{~nm}$ are presented in Fig. 7 as a function of the product of the droplet $(Q)$ and $\mathrm{AP}(q)$ charges. The measurements are compared to the Dépée et al. (2019) extended model (solid line) for the four AP charges, considering the AP and droplet charge uncertainties. There is a good agreement between model and measurements, which indicates that the analytical expression of the electrostatic forces (Eq. 10) reliably describes the observations.

Indeed, an important charge influence is measured, increasing or decreasing the $\mathrm{CE}$ up to 2 orders of magnitude for large negative or positive charge products, respectively, compared to the theoretical $\mathrm{CE}$ value disregarding the electrostatic effects (dashed line in Fig. 7). This is due to the Coulomb inverse square term in the electrostatic forces' Eq. (10) which dominates - attracting or repelling the APs from the droplet depending on whether the AP and droplet charges have unlike or like signs.

For small positive charge products (approximately $0 \leq$ $\left.q \times Q \leq 10^{6}|e| \times|e|\right)$, an increase in CE with a factor of more than 3 is measured compared to the theoretical $\mathrm{CE}$ value without electrostatic forces. This fact truly emphasises the contribution of the short-range attractive term in Eq. (10), which attracts the APs toward the droplet even though the droplet and AP charges have like signs. Indeed, as previously stated, this term prevails for small charge products (Dépée et al., 2019). 
Table 4. CE measurements.

\begin{tabular}{lrrrrrrrr}
\hline \multirow{2}{*}{$a_{\text {wet }}(\mathrm{nm})$} & & \multicolumn{7}{c}{$Q(|e|)$} \\
\cline { 3 - 8 } & $q(|e|)$ & $\begin{array}{r}9.6 \times 10^{4} \\
\pm 4.3 \times 10^{3}\end{array}$ & $\begin{array}{r}3.0 \times 10^{4} \\
\pm 1.9 \times 10^{3}\end{array}$ & $\begin{array}{r}5.0 \times 10^{3} \\
\pm 8.4 \times 10^{2}\end{array}$ & $0 \pm 6.0 \times 10^{2}$ & $-5.0 \times 10^{3}$ & $-1.0 \times 10^{4}$ & $-3.0 \times 10^{4}$ \\
& & & $\pm 7.7 \times 10^{2}$ & $\pm 8.7 \times 10^{2}$ & $\pm 1.4 \times 10^{3}$ \\
\hline \multirow{2}{*}{$175 \pm 3$} & $-10 \pm 1$ & $3.91 \times 10^{-2}$ & $2.44 \times 10^{-2}$ & $3.47 \times 10^{-3}$ & $4.17 \times 10^{-3}$ & $5.58 \times 10^{-3}$ & $9.81 \times 10^{-4}$ & $2.55 \times 10^{-4}$ \\
& $-20 \pm 2$ & $6.77 \times 10^{-2}$ & $3.47 \times 10^{-2}$ & $6.99 \times 10^{-3}$ & $5.07 \times 10^{-3}$ & $4.25 \times 10^{-3}$ & $9.17 \times 10^{-4}$ & $4.12 \times 10^{-5}$ \\
\hline $260 \pm 3$ & $-11 \pm 1$ & $2.41 \times 10^{-2}$ & $1.30 \times 10^{-2}$ & $3.25 \times 10^{-3}$ & $2.97 \times 10^{-3}$ & $2.14 \times 10^{-3}$ & $1.34 \times 10^{-3}$ & $1.93 \times 10^{-4}$ \\
& $-30 \pm 3$ & $7.91 \times 10^{-2}$ & $2.31 \times 10^{-2}$ & $7.96 \times 10^{-3}$ & $5.75 \times 10^{-3}$ & $3.47 \times 10^{-3}$ & $2.57 \times 10^{-3}$ & $4.97 \times 10^{-5}$ \\
\hline $346 \pm 4$ & $-10 \pm 1$ & $2.24 \times 10^{-2}$ & $8.98 \times 10^{-3}$ & $3.03 \times 10^{-3}$ & $1.86 \times 10^{-3}$ & $1.84 \times 10^{-3}$ & $1.05 \times 10^{-3}$ & $5.20 \times 10^{-4}$ \\
& $-34 \pm 3$ & $4.58 \times 10^{-2}$ & $1.40 \times 10^{-2}$ & $5.39 \times 10^{-3}$ & $3.91 \times 10^{-3}$ & $2.90 \times 10^{-3}$ & $2.23 \times 10^{-3}$ & $3.60 \times 10^{-5}$ \\
& $-71 \pm 7$ & $9.17 \times 10^{-2}$ & $3.25 \times 10^{-2}$ & $1.70 \times 10^{-2}$ & $7.33 \times 10^{-3}$ & $5.51 \times 10^{-3}$ & $2.88 \times 10^{-3}$ & $2.21 \times 10^{-5}$ \\
\hline $432 \pm 5$ & $-22 \pm 2$ & $3.74 \times 10^{-2}$ & $1.49 \times 10^{-2}$ & $3.22 \times 10^{-3}$ & $2.49 \times 10^{-3}$ & $1.85 \times 10^{-3}$ & $2.44 \times 10^{-3}$ & $1.25 \times 10^{-4}$ \\
& $-52 \pm 5$ & $7.62 \times 10^{-2}$ & $4.13 \times 10^{-2}$ & $1.13 \times 10^{-2}$ & $3.23 \times 10^{-3}$ & $3.23 \times 10^{-3}$ & $4.17 \times 10^{-3}$ & $1.06 \times 10^{-4}$ \\
& $-90 \pm 9$ & $1.77 \times 10^{-1}$ & $3.55 \times 10^{-2}$ & $1.83 \times 10^{-2}$ & $6.90 \times 10^{-3}$ & $4.75 \times 10^{-3}$ & $4.56 \times 10^{-3}$ & $2.43 \times 10^{-5}$ \\
\hline
\end{tabular}

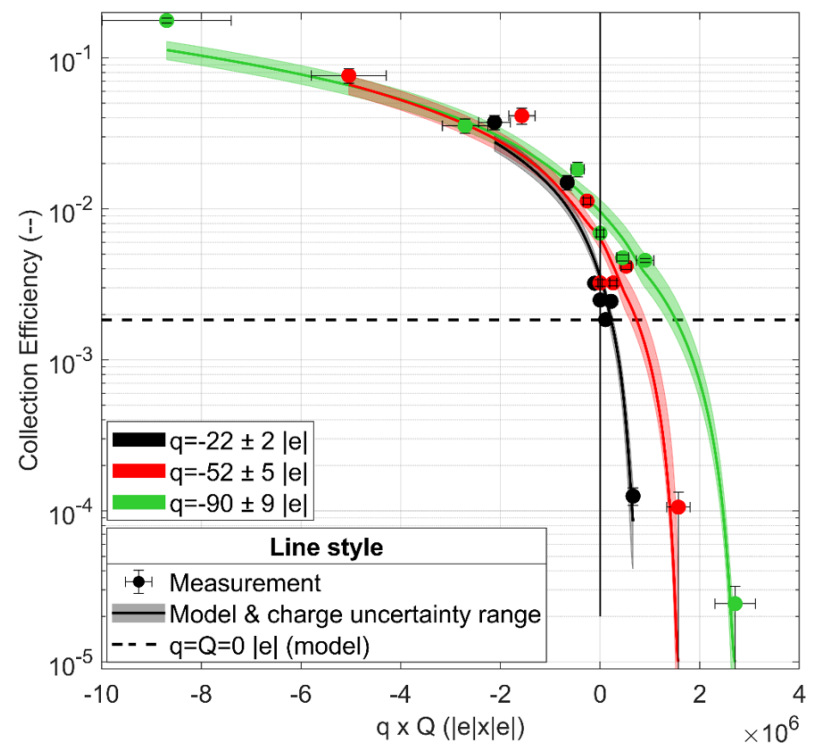

Figure 7. $\mathrm{CE}$ measurement as a function of the product of the droplet $(Q)$ and $\mathrm{AP}(q)$ charges for the wet AP radius of $432 \mathrm{~nm}$ and a droplet radius of $48.5 \pm 1.1 \mu \mathrm{m}$. The experimental conditions are summarised in Table 5. Colour code informs about the AP charge. The dashed line represents the theoretical $\mathrm{CE}$ value disregarding the electrostatic forces (given the air parameters $1{ }^{\circ} \mathrm{C}, 1 \mathrm{~atm}, 95 \%$ of relative humidity). The solid line is the interpolation of the Dépée et al. (2019) extended model (with the charge uncertainty range) for the respective $\mathrm{CE}$ measurements at a given AP charge.

Note that the same influence of the charge product on the $\mathrm{CE}$ is observed for the other three wet AP radii - the CE varies up to 4 orders of magnitude.

\subsubsection{Effect of the AP charge on the collection efficiency for a neutral droplet}

In Fig. 8, the CE measurements (circle) for a neutral droplet $(Q=0 \pm 600|e|)$ are presented for the four wet AP radii - referred to by the colour code - with the respective theoretical $\mathrm{CE}$ values (triangle). The dashed line represents the theoretical CE value without electrostatic forces.

Note that the contribution of the electrostatic forces seems insignificant for an AP charge of about $\sim-10$ elementary charges and an AP radius of 346 and $260 \mathrm{~nm}$ as well as an AP of $432 \mathrm{~nm}$ with -20 elementary charges. Indeed, these measurements are very close to the theoretical ones with no consideration of electrostatic forces. Several microphysical effects have probably an equivalent contribution on the CE measurements such as electrostatic, thermophoretic and diffusiophoretic forces, in addition to AP diffusion, weight and inertia.

However, at a given AP radius, an increase in the CE is observed when the number of elementary charges on the APs is larger. Note that this increase appears even though the droplet is neutral (or poorly charged considering the charge uncertainty of 600 elementary charges). For example, given an AP radius of $346 \mathrm{~nm}$, the $\mathrm{CE}$ is multiplied by almost a factor of 4 when the AP charge increases from -10 to -71 elementary charges. It highlights the contribution of the short-range attractive term in Eq. (10), showing the presence of a surface charge distribution on the droplet formed by the partial influence of the AP electrostatic field on it. In the current case, this is the only contribution since the droplet is neutral and the Coulomb inverse square term is zero in Eq. (10). This is an important result since, to our knowledge, there is no experimental observation of the short-range attractive term on the $\mathrm{CE}$ in the previous studies of the literature. Here, the good agreement between measured (circle) and modelled (trian- 
Table 5. Key features of the In-CASE setup.

\begin{tabular}{|c|c|}
\hline Feature & Numerical value \\
\hline \multicolumn{2}{|l|}{ Collision chamber's parameters } \\
\hline Height of the collision chamber $\left(H_{\text {In-CASE }}\right)$ & $1 \mathrm{~m}$ \\
\hline Distance between droplet injection and AP injection & $\approx 10 \mathrm{~cm}$ \\
\hline Diameter of the collision chamber & $5 \mathrm{~cm}$ \\
\hline Impaction cup diameter & $2.5 \mathrm{~cm}$ \\
\hline AP flow rate in the DMA & Between 0.4 and $1.2 \mathrm{~L} \mathrm{~min}^{-1}$ (following the selected AP radius) \\
\hline Clean air adding at the inlet of the aerosol charger & Between 0.3 and $1.1 \mathrm{~L} \mathrm{~min}^{-1}$ (following the selected AP radius) \\
\hline AP flow rate in the aerosol charger & $1.5 \mathrm{~L} \mathrm{~min}^{-1}$ \\
\hline AP flow rate in the collision chamber $\left(Q_{\text {In-CASE, c }}\right)$ & $1.5 \mathrm{~L} \mathrm{~min}^{-1}$ \\
\hline Flow velocity in the collision chamber $\left(V_{Q}\right)$ & $1.3 \mathrm{~cm} \mathrm{~s}^{-1}$ \\
\hline Flow rate of the upward Argon at the inlet of AP/droplet separator & $0.4 \mathrm{~L} \mathrm{~min}^{-1}$ \\
\hline Flow rate of the upward Argon in the impaction cup & $1.4 \mathrm{~cm} \mathrm{~s}^{-1}$ \\
\hline $\begin{array}{l}\text { AP and Argon flow rate at the outlet of In-CASE chamber } \\
\text { (toward the HEPA filter) }\end{array}$ & $1.9 \mathrm{Lmin}^{-1}$ \\
\hline Air pressure in the collision chamber $\left(P_{\text {air }}\right)$ & $1 \mathrm{~atm}$ \\
\hline Temperature in the collision chamber $\left(T_{\text {air }}\right)$ & $1.08 \pm 0.12{ }^{\circ} \mathrm{C}$ \\
\hline Relative humidity in the collision chamber (RH) & $95.1 \pm 0.2 \%$ \\
\hline Duration of experiments $(\Delta t)$ & From 3 to $6 \mathrm{~h}$ (related to the expected APs mass in droplets) \\
\hline \multicolumn{2}{|l|}{ AP parameters } \\
\hline Selected dry AP radius during experiment $(a)$ & $100,150,200$ or $250 \mathrm{~nm}$ \\
\hline Growth factor of the APs (GroF) & $\begin{array}{l}\text { Between } 1.73 \text { and } 1.75 \text { (following the mean levels of relative humidity } \\
\text { for the four separated AP radii) }\end{array}$ \\
\hline Density of sodium fluorescein ( $\left.\rho_{\text {fluorescein }}\right)$ & $1580 \mathrm{~kg} \mathrm{~m}^{-3}$ \\
\hline Density of the wet APs $\left(\rho_{\mathrm{AP}}\right)$ & $\approx 1110 \mathrm{~kg} \mathrm{~m}^{-3}$ \\
\hline AP terminal velocity & $\begin{array}{l}\leq 10^{-3} \mathrm{~cm} \mathrm{~s}^{-1} \text { (equal to } 8 \times 10^{-4} \mathrm{~cm} \mathrm{~s}^{-1} \text { for the larger selected dry AP } \\
\text { radius } 250 \mathrm{~nm} \text { ) }\end{array}$ \\
\hline AP residence time in the collision chamber & $\approx 80 \mathrm{~s}$ \\
\hline $\begin{array}{l}\text { Total AP concentration (single and multiple charged } \\
\text { at the DMA's outlet) }\end{array}$ & $\begin{array}{l}\text { From } 3 \times 10^{4} \mathrm{~cm}^{-3}(\text { for } a=100 \mathrm{~nm} \text { and } q=-10 \pm 1|e|) \text { to } 2 \times 10^{3} \mathrm{~cm}^{-3} \\
\text { (for } a=250 \mathrm{~nm} \text { and } q=-90 \pm 9|e| \text { ) }\end{array}$ \\
\hline AP charge $(q)$ & $\begin{array}{l}\text { From }-10 \pm 1 \text { to }-90 \pm 9 \text { elementary charges (following the selected AP } \\
\text { radius) }\end{array}$ \\
\hline \multicolumn{2}{|l|}{ Droplet parameters } \\
\hline Droplet radius $(A)$ & $48.5 \pm 1.1 \mu \mathrm{m}$ \\
\hline Droplet generation frequency $\left(F_{\mathrm{d}}\right)$ & $25 \mathrm{~Hz}$ \\
\hline Droplet terminal velocity $\left(U_{A, \infty}\right)$ & $\approx 25 \mathrm{~cm} \mathrm{~s}^{-1}$ \\
\hline Number of injected droplets during experiments $\left(N_{\mathrm{d}}\right)$ & From 270000 to 540000 (related to the expected APs mass in droplets) \\
\hline Observed distance between two successive droplets & $\approx 9 \mathrm{~mm} \approx 180$ droplet radii \\
\hline Droplet residence time in the collision chamber & $\approx 4 \mathrm{~s}$ \\
\hline Droplet charge $(Q)$ & From $-3.0 \times 10^{4} \pm 1.4 \times 10^{3}$ to $9.6 \times 10^{4} \pm 4.3 \times 10^{3}$ elementary charges \\
\hline Droplet charge after neutralisation $(Q)$ & $0 \pm 600$ elementary charges \\
\hline $\begin{array}{l}\text { Droplet evaporation between the injection and the end } \\
\text { of the collision chamber }\end{array}$ & $\approx 0.3 \%$ \\
\hline Sodium chloride concentration in the pure water & $3.3 \mathrm{gL}^{-1}$ \\
\hline
\end{tabular}




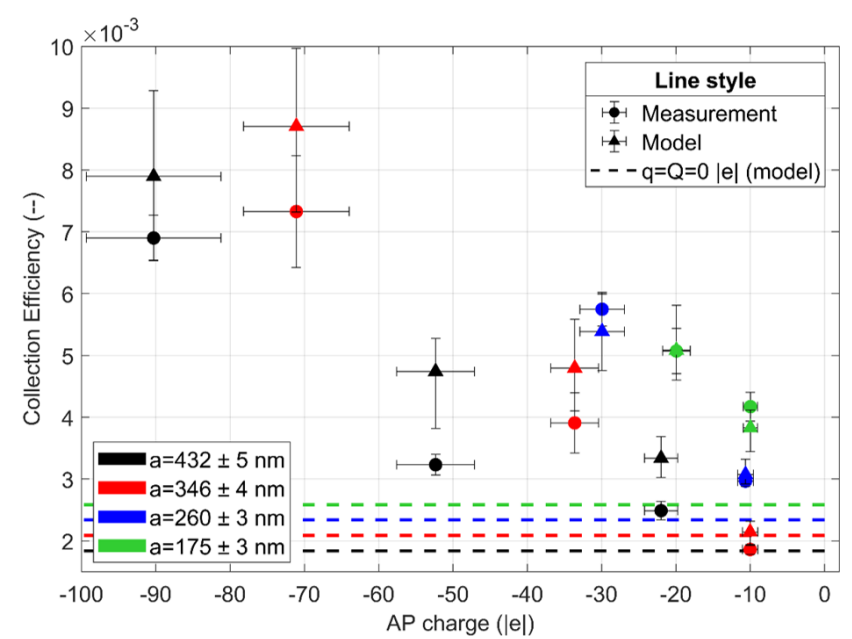

Figure 8. CE measurement (circle) as a function of the AP charge ( $q$ ) for the four wet AP radii (colour code). The respective modelled CEs are also presented (triangle). The droplet is neutral with a radius of $48.5 \pm 1.1 \mu \mathrm{m}$. The experimental conditions are summarised in Table 5. The dashed line represents the theoretical CE value disregarding the electrostatic forces (given the air parameters $1{ }^{\circ} \mathrm{C}, 1 \mathrm{~atm}, 95 \%$ of relative humidity). The vertical error bars for the modelled CEs consider the AP and droplet charges uncertainties.

gle) CEs confirms that the analytical expression of the shortrange attractive term in Eq. (10) is reliable.

For a given AP charge, an increase in the CE is measured when the AP radius decreases, probably due to the increase in the electrical mobility of APs. This is in line with the numerical results of Dépée et al. (2019) even though electrostatic effects are not the only contribution involved in this CE increase. Indeed, the Brownian motion of the APs increases for smaller APs and enhances the collision between the droplet and APs.

Moreover, the curve slope could be increased for a decrease in the AP radius since the electrical mobility increases, but this trend is not visible in Fig. 8. It can be due to the uncertainties on the CE measurements, the droplet neutralisation and the AP charge.

\subsubsection{Comparison with existing models}

\section{Kraemer and Johnstone (1955) prediction}

To describe the impact of the electric charge on the $\mathrm{CE}$, there is the well-known prediction of Kraemer and Johnstone (1955), summarised in Eq. (11):

$\mathrm{EC}_{\mathrm{KJ}}=\left(\frac{Q}{\pi \varepsilon_{0} A^{2} \Delta U}\right)\left(\frac{q \times C_{u}}{6 \pi \eta_{\mathrm{air}} a}\right)$,

with $\eta_{\text {air }}$ the dynamic viscosity of air, $C_{u}$ the StokesCunningham slip correction factor (defined in Appendix A of Dépée et al., 2019) and $\Delta U$ the droplet fall velocity rela-

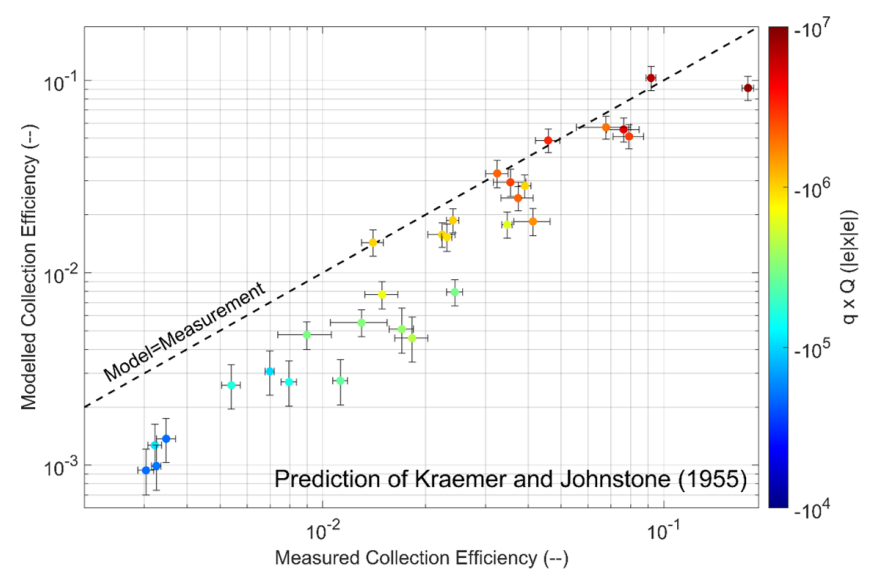

Figure 9. Modelled CE from the prediction of Kraemer and Johnstone (1955) as a function of the measured CE. The droplet radius is $48.5 \pm 1.1 \mu \mathrm{m}$. Only the negative charge products for the four AP radii are considered here, represented by the colour code. The experimental conditions are summarised in Table 5.

tive to the AP fall velocity. The latter is assumed to be equal to $\left|U_{A, \infty}-U_{a, \infty}\right|$, where $U_{a, \infty}$ is the AP settling velocity.

Since this prediction models the contribution of the attractive Coulomb forces on the CE, only the CE measurements with a negative charge product for the four AP radii are compared. In Fig. 9, the modelled CE from the prediction of Kraemer and Johnstone (1955) as a function of the measured CE is presented. The horizontal error bars are the measurement uncertainties, while the vertical ones are the extreme theoretical CE values considering the extreme droplet and AP charges (by adding or subtracting the charge uncertainties). It is shown that the prediction of Kramer and Johnstone (1955) accurately describes the observation for the large charge products (red colour), but the discrepancies between model and measurement increase when the charge product decreases. Indeed, the less AP and droplet are electrically charged, the more the model underestimates the CE compared to the observations. This is due to the formula which only models the attractive Coulomb forces and disregards the other effects like the AP weight, the AP inertia and the AP diffusion, which tend to increase the CE as well as the diffusiophoretic and the thermophoretic forces (Dépée et al., 2021). Consequently, the prediction gives better agreement for large charge products where the attractive Coulomb forces dominate the other effects on the AP collection. This case illustrates the strong interest of using Lagrangian models like the one of Dépée et al. (2019), which considers all microphysical effects involved in the in-cloud AP collection and especially their coupling.

Note that Wang et al. (1983) also compared their CE measurements with this prediction, finding good agreement since they considered between $-10^{7}$ and $-10^{8}$ elementary charges on droplets and between 1 and 13.5 elementary charges on APs. So, their charge products were larger than the ones used 
in the present study, and they had no combined effect - the attractive Coulomb force was by far the only significant contribution. It can explain why their comparison with the prediction of Kraemer and Johnstone (1955) is better than the ones presented in Fig. 9. Since most of the measurements of Wang et al. (1983) are for a droplet radius of $250 \mu \mathrm{m}$, they are not comparable to the present ones, which are significantly much smaller $(A=48.5 \pm 1.1 \mu \mathrm{m})$.

\section{Dépée et al. (2019) extended model}

In Fig. 10, the modelled $\mathrm{CE}$ from the extended model of Dépée et al. (2019) as a function of the measured CE is presented. The modelled CEs are calculated from the experimental parameters (AP density, air temperature, pressure, and relative humidity as well as the sizes and charges), and the CE values less than $10^{-5}$ are set to $10^{-5}$ to avoid an excessive computation time (Dépée et al., 2019). The horizontal error bars are the measurement uncertainties, while the vertical ones are the extreme theoretical CE values considering the extreme droplet and AP charges (by adding or subtracting the charge uncertainties). The colour code corresponds to the different droplet radii studied.

A good accordance between the model and the CE measurements is shown. Indeed, it appears that there are as many data points above the "Model = Measurement" line as below, meaning that the model overestimates as much as underestimates the observations. Thus, it can be assumed that there are no missing or unnecessary microphysics effects in the $\mathrm{CE}$ modelling. Moreover, the mean difference between the modelled CEs and the 70 measured CEs is $66 \%$. This is a reasonable value for a microphysics parameter such as the collection efficiency which varies on several orders of magnitude, especially since the value was calculated disregarding the different uncertainties (error bars in Fig. 10) and was as a result over-evaluated.

Nevertheless, six data points seem inconsistent with discrepancies between model and measurements from $150 \%$ to $1000 \%$, occurring for the smallest CE values in Fig. 10 (lower left). Note that the discrepancies should be even worse since the modelled CEs, set to $10^{-5}$, are actually much lower. By examining these data points, it appears that the measured $\mathrm{AP}$ masses in the droplet impaction cup $-m_{\mathrm{AP}, \mathrm{d}}$ in Eq. (1) are very close to the detection limit of the spectrometer used. Moreover, for the experimental conditions, the model predicts AP masses in the droplets lower than the detection limit since the Coulomb inverse square term in Eq. (10) was very repulsive. So, the assumption can be made that a pollution occurred during the various steps of the protocol (end of experiment, disassembly of the chamber's bottom to reach the droplet impaction cup, change of room for the analysis, etc.). Note that the detection limit of the spectrometer is $10^{-15} \mathrm{~kg}$ (for the nominal analysis volume considered), which only represents 10 APs with a dry radius of $250 \mathrm{~nm}$ deposited on the droplet impaction cup. Thus, there exists an important uncertainty in these CE measurements related to a possible contamination. This is difficult to quantify, but the low uncertainties of the $\mathrm{CE}$ measurements below $10^{-4}$ were increased in Fig. 10. To reduce this potential pollution, it would be necessary to work in a clean room or increase the experiment duration to avoid detection problem. However, for these data points the experiment duration was almost $6 \mathrm{~h}$, and beyond this duration, stability problems of the piezoelectric droplet generator were frequent.

However, a reasonable agreement between the extended model of Dépée et al. (2019) and the CE measurements is observed. As a reminder, the mean discrepancy was overevaluated at $66 \%$, which is suitable to describe a microphysical parameter varying on several orders of magnitude for the collection efficiency. Furthermore, if the six inconsistent values are removed, the mean discrepancy on the 63 remaining CE measurements decreases from $66 \%$ to $38 \%$.

The $38 \%$ of discrepancy between the Dépée et al. (2019) extended model and the measurements can be attributed to the dispersion of the AP charge distribution. Indeed, it was not possible to characterise the AP charge distribution, which remains an important uncertainty. Moreover, the AP size distribution was assumed to be monodispersed, but a dispersion exists, even if very small, which depends on the spectral bandwidth of the DMA. This one can induce some larger (or smaller) APs inside the AP charger which can get an electric charge significantly larger (or smaller) than the predicted one since the charging process is roughly proportional to the AP surface. Then, in the In-CASE chamber, some larger (or smaller) APs with a larger (or smaller) electric charge can interact with the droplets and notably change the final AP mass collected by the droplets during an experiment $\left(m_{\mathrm{AP}, \mathrm{d}}\right)$. Another possible explanation is the differences in temperature and relative humidity between the top and the bottom chamber, respectively less than $1{ }^{\circ} \mathrm{C}$ and $4 \%$ (addressed in Dépée et al., 2021). It could induce local discrepancies during the AP travel time in the chamber in terms of AP density and radius (through the hygroscopicity) or thermophoretic and diffusiophoretic forces which can change the likelihood of being collected by the droplets and then slightly change $m_{\mathrm{AP}, \mathrm{d}}$. See Dépée et al. (2021) for a discussion of the influence of these two latter forces on the CE.

\section{Conclusions}

In-CASE (In-Cloud Aerosol Scavenging Experiment) was developed to conduct a series of experiments evaluating the contribution of microphysical effects on the AP collection by falling cloud droplets. For this purpose, all the parameters influencing the collection efficiency (CE) are controlled - i.e. the AP and droplet sizes, the AP and droplet electric charges, and the relative humidity. A first campaign was performed to study the influence of the relative humidity, which is the topic of Part I (Dépée et al., 2021). This cur- 


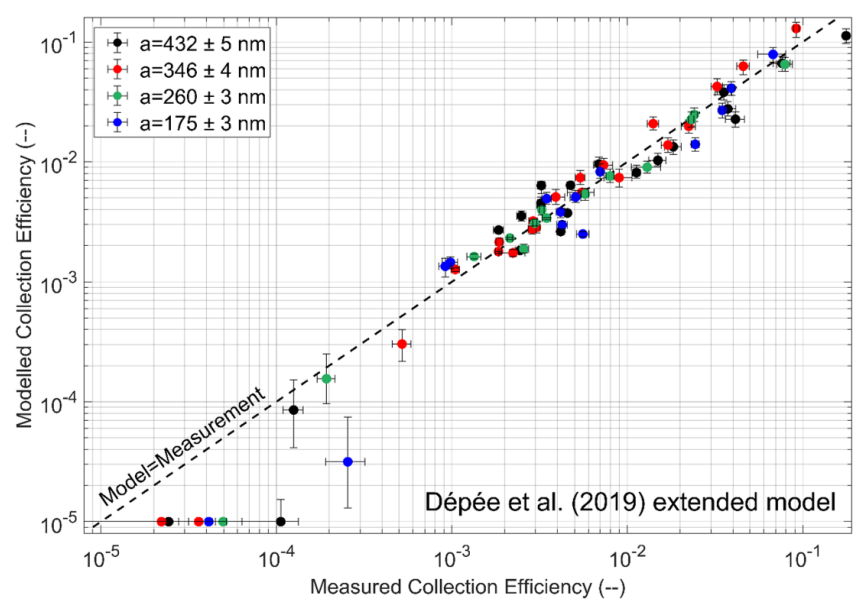

Figure 10. Modelled CE from the extended model of Dépée et al. (2019) as a function of the measured CE. The droplet radius is $48.5 \pm 1.1 \mu \mathrm{m}$. The colour code referrers to the AP radius. The experimental conditions are summarised in Table 5.

rent study was dedicated to a second topic - aiming the impact of the electric charge on the CE. Furthermore, the CE measurements allow us to validate existing models like the Lagrangian one of Dépée et al. (2019) which considers all microphysical effects involved in the AP collection by cloud droplets. Indeed, the literature lacks baseline data to get a suitable comparison with the modelling since most of the previous studies failed to control all parameters influencing the CE like the AP and droplet sizes and charges as well as the relative humidity (Beard, 1974; Lai et al., 1978; Barlow and Latham, 1983; Byrne and Jennings, 1993). Even though some studies stand out (Wang and Pruppacher, 1977; Wang et al., 1983), no one examined the influence of the electrostatic forces when the droplet and AP charges had like signs. Thus, the short-range attractive term from the analytical expression of the electrostatic forces - Eq. (10) - used in the current Lagrangian models (Tinsley and Zhou, 2015; Dépée et al., 2019) has never been experimentally validated or at least emphasised.

In the new CE dataset, the APs and droplets are accurately charged through custom-made droplet and AP chargers detailed above. Since both charge polarities are found in clouds (Takahashi, 1973), the droplets were negatively as well as positively charged during experiments. Moreover, several amounts of elementary charges on the droplet were considered to represent a neutral droplet but also the weakly and strongly charged droplets respectively found in stratiform and convective clouds (Takahashi, 1973). The AP charge varied from zero to $-90 \pm 9$ elementary charges depending on the AP size to represent different amounts of elementary charges encountered in the atmosphere, particularly the ones of radioactive APs. The relative humidity was maximised in this experimental work $(95.1 \pm 0.2 \%)$ with a mean temperature in the collision chamber $\left(1.08 \pm 0.12^{\circ} \mathrm{C}\right)$ stable and comparable with the other study in the companion paper: Part I (Dépée et al., 2021). Thus, the thermophoretic and diffusiophoretic contributions on the CE measurements were reduced as much as possible. Nevertheless, since Dépée et al. (2021) measured a significant contribution for a comparable relative humidity level, these two forces were still added to the Dépée et al. (2019) model for a reliable modelmeasurement comparison. Finally, the droplet radius was $48.5 \pm 1.1 \mu \mathrm{m}$, and four wet AP radii were used - from $175 \pm 3$ to $432 \pm 5 \mathrm{~nm}$. Note that the hygroscopicity of the sodium fluorescein salt was considered in the calculation of the wet AP radius and the AP density.

From the 70 measurements obtained, an influence of the electric charges of 4 orders of magnitude on the $\mathrm{CE}$ was observed, strongly increasing or decreasing the CE for large charge products, respectively negative or positive. An increase in the CE was also measured by considering more elementary charges on the APs even though the droplets were neutral (within uncertainties). This observation is an important result since it emphasises the contribution of the shortrange attractive term in the electrostatic forces, Eq. (10). It validates a surface charge distribution on the droplet, formed by the partial influence of the AP electric field on it, which has never been experimentally shown, to our knowledge, in the literature before.

The CE measurements with opposite signs on the droplet and AP were compared to the prediction of Kraemer and Johnstone (1955), giving good agreements for large negative charge products where the Coulomb attractive forces prevail over the other dynamic effects. This is in line with the work of Wang et al. (1983), who also obtained good agreement, considering another droplet radius $(250 \mu \mathrm{m})$ and larger negative charge products. However, in the present study, an increase in the discrepancies between the prediction and the measurement was measured when reducing the number of elementary charges. This is due to the electrostatic forces not being the only effect involved in the AP collection. There is actually a coupling of electrostatic, diffusiophoretic, and thermophoretic forces as well as the AP diffusion, weight and inertia. Thus, when the charge product is not strong enough (gets significantly smaller than $10^{7}|e| \times|e|$ ), Lagrangian models such as the one of Dépée et al. (2019) remain the best estimation of the $\mathrm{CE}$.

Finally, the CE measurements were also compared to the extended model of Dépée et al. (2019), showing a really good description of the observed effects. Indeed, the mean discrepancy of the modelling and the 70 measurements was $66 \%$, which is suitable for a microphysical effect varying on several orders of magnitude like the collection efficiency. This value was even better when six inconsistent measurements, probably contaminated, were disregarded - as it decreases from $66 \%$ to $38 \%$. Moreover, note that the model overestimates as much as underestimates the observations so that the discrepancies probably result from remaining uncertainties 
(like the dispersion of the AP charge distribution) instead of a missing microphysical effect in the CE modelling.

To conclude, 70 new $\mathrm{CE}$ measurements are now available that include the influence of the electric charges, showing significant differences with the previous CE measurements and theoretical values from the literature which disregard the electrostatic forces. Thus, it appears to be essential to study the impact of the new baseline data in a cloud model like DESCAM (Detailed Scavenging Model, Flossmann et al., 1985) to examine the influence of the electric charges on the total wet AP removal in the atmosphere. This could strongly affect the atmospheric AP removal because the cloud droplets are known to be charged (Takahashi, 1973) as well as the atmospheric APs, especially when those APs are radioactive (Clement and Harrison, 1992). Indeed, Dépée et al. (2019) estimated that the electric charge of the radioactive APs emitted after the Fukushima accident in 2011 was up to 600 elementary charges. Thus, AP removal could be substantially affected by the electrostatic forces in cloud and significantly change the ground contamination after a discharge of radioactive materials from a nuclear accident. Since the new Lagrangian model of Dépée et al. (2019) showed an accurate description of the influence of the electric charges (and also of the relative humidity, studied in Part I, Dépée et al., 2021) on the CE, the latter constitutes a simple, convenient and rapid manner to obtain a $\mathrm{CE}$ evaluation for its incorporation in cloud models. 


\section{Appendix A: AP charger}

\section{A1 AP charging relationship's acquisition}

The AP charging relationships were obtained by performing ex situ experiments with the setup presented in Fig. A1. A nominal AP flow goes through the charger with a monodispersed AP size distribution. At the charger's outlet, the flow of charged AP is subdivided $-0.6 \mathrm{~L} \mathrm{~min}^{-1}$ is directed to a condensation particle counter (CPC; TSI 3787) to deduce the concentration number of $\mathrm{AP}$ in the charger $\left(C_{N, \mathrm{AP}}\right)$, while the other part goes toward an electrometer (TSI 3068A) to measure the current $\left(I_{\text {elect }}\right)$ due to the charge evacuation. Before entering the CPC, APs are neutralised to avoid any deposition on the metallic walls of the CPC, and then the AP flow passes through a diffusion battery to filter the fine particles produced during the discharges inside the charger. The mean AP charge $(\langle q\rangle)$ was then calculated from Eq. (A1) with the elementary charge $(e)$ and the AP flow rate in the electrometer $\left(Q_{\text {elect }}\right)$ :

$\langle q\rangle=\frac{I_{\text {elect }}}{e \times C_{N, \mathrm{AP}} \times Q_{\text {elect }}}$.

Several AP flow rates in the charger $\left(Q_{\text {charger }}\right)$ were considered to study the AP penetration. When $Q_{\text {charger was less }}$ than $0.7 \mathrm{~L} \mathrm{~min}^{-1}$, clean air was added before the CPC to maintain a CPC flow rate of $0.6 \mathrm{~L} \mathrm{~min}^{-1}$ - this part is presented in red in Fig. A1. From these experiments, it was found that $Q_{\text {charger }}=1.5 \mathrm{~L} \mathrm{~min}^{-1}$ maximises the AP penetration through the charger. Note that the AP penetration is defined, at the charger's outlet, as the AP number concentration when the charger is switched on over the AP number concentration when the latter is switched off.

\section{A2 Validation}

The setup (Fig. A1) was conducted with the charger turned off to measure the mean AP charge after the DMA. One elementary charge was found on APs, which validates the fact that the multiple charged APs are stopped at the DMA's inlet by the aerodynamic impactor. Thus, the assumption made that the AP size distribution is monodispersed after the DMA is justified. The AP charge was also analysed during $5 \mathrm{~h}-$ no AP charge modification was measured over time. Moreover, the saturated AP charges visible in Fig. 4 for a tungsten wire potential less than $-12.5 \mathrm{kV}$ were also compared to the theoretical values of Pauthenier and Moreau-Hanot (1932) giving a good agreement.

Note that two other characterisations were made during these ex situ experiments, like the determination of the ion current between the grounded cylinder and the tungsten wire (Fig. 3) or the discharge frequencies - both of these parameters are related to the tungsten wire potential. These curves were used to precisely identify the discharge regime of the charger (Unger, 2001) - the negative Trichel regime which provides a large discharge frequency and then a spatially homogeneous particle charging around the tungsten wires.

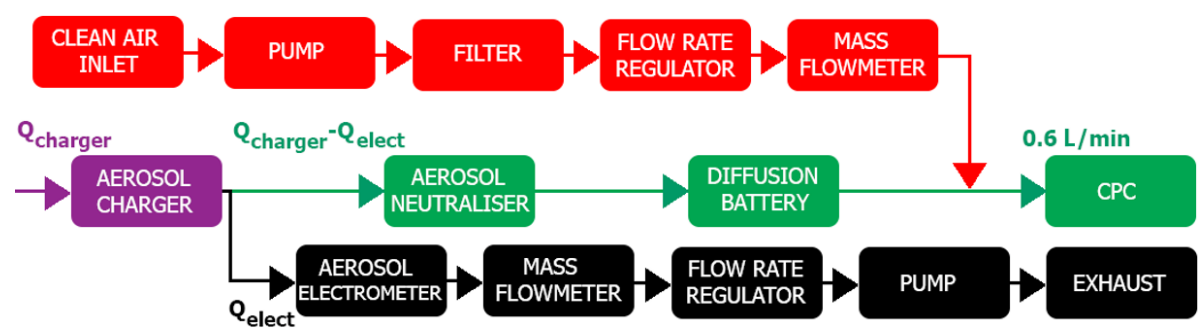

Figure A1. Setup to obtain the AP charging relationship. The red dashed rectangle is the part added to study the AP penetration through the charger. 


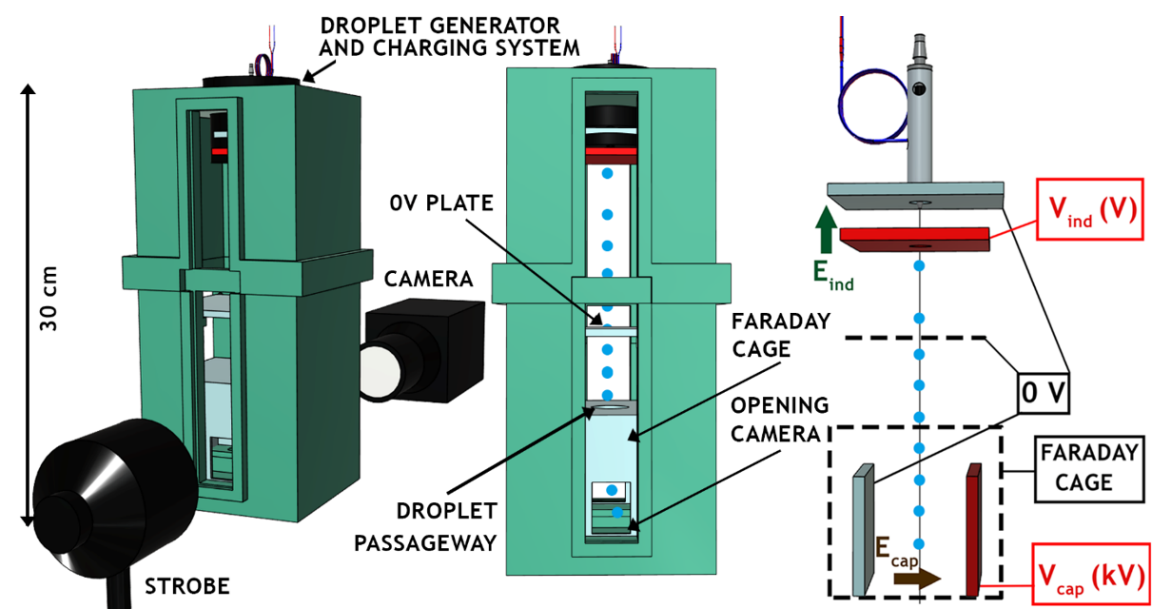

Figure B1. Setup to obtain the droplet charging relationship - (left and centre) 3D view and (right) schema (not to scale).

\section{Appendix B: Droplet charging relationship obtention}

\section{B1 Overview}

Figure B1 presents the setup used in ex situ experiments to measure the droplet charge where the charging relationship in Fig. 6 comes from. The housing made with a 3D printer containing the droplet injector and the charging system (detailed in Sect. 2.5) - is set above a capacitor composed of one neutral potential plate and another plate connected to a high potential $\left(V_{\text {cap }}\right)$. In the latter, pictures are obtained by optical shadowgraphy to get the droplet trajectories. The electric field $\left(E_{\text {cap }}\right)$ induced in the capacitor disturbs the droplet motion according to its electric charge. Thus, the droplet charge is evaluated by finding the one which fits the best with the theoretical droplet trajectory - deduced from the Newton's second law - and the measured droplet trajectories. A Faraday cage ensures the electric field at the capacitor $\left(E_{\text {cap }}\right)$ has no effect on the electric field at the electrostatic inductor $\left(E_{\text {ind }}\right)$. Since this is not a proper Faraday cage because of the holes for droplets and the camera, a horizontal metallic perforated plate is added below the droplet generator housing and connected to the neutral potential to prevent the electric field $\left(E_{\text {cap }}\right)$ from changing the droplet charge.

\section{B2 Droplet charge evaluation}

A series of 200 pictures pairs, with each one dephased from the other by a known time step $(\Delta t)$, are obtained by optical shadowgraphy at the level of the capacitor. A circle Hough transform is then applied to evaluate the droplet centres in every picture - an example is given in Fig. B2 (left), where the two droplets from a picture are represented by two black crosses, while the blue cross is the detected droplet from the coupled picture dephased by $\Delta t$.
Then, the instantaneous droplet velocity $\boldsymbol{U}_{\boldsymbol{D}_{\mathbf{0}}}(\boldsymbol{t})=$ $U_{D_{0}, x} \boldsymbol{u}_{\boldsymbol{x}}+U_{\infty, A} \boldsymbol{u}_{\boldsymbol{y}}$ at the first detected droplet position $\left(D_{0}\right)$ of coordinates $\left(x_{D_{0}} y_{D_{0}}\right)$ is calculated, and the vertical velocity component $\left(U_{\infty, A}\right)$ determines the droplet radius $(A)$ by reversing the Beard (1976) model. Here, the circle Hough transform is not used to calculate the droplet radius like during CE experiments - see Fig. 8 (right) from Part I, Dépée et al. (2021). Indeed, for these experiments the magnification of the camera is the lowest in order to extend the field of view. As a consequence, the uncertainty on the droplet size would be too large.

Finally, the theoretical droplet trajectories at the capacitor are deduced by solving Newton's second law where the buoyancy force $\left(\boldsymbol{F}_{\text {buoy }}\right)$, the drag force $\left(\boldsymbol{F}_{\text {Drag }}\right)$ and the electrostatic force $\left(\boldsymbol{F}_{\boldsymbol{E}_{\text {cap }}}\right)$ related to the electric field $\left(E_{\text {cap }}\right)$ at the capacitor are considered, summarised in Eq. (B1):

$$
\left\{\begin{array}{l}
m_{\mathrm{D}} \frac{\mathrm{d} \boldsymbol{U}_{\mathrm{D}}(t)}{\mathrm{d} t}=\boldsymbol{F}_{\text {buoy }}+\boldsymbol{F}_{\text {Drag }}+\boldsymbol{F}_{\boldsymbol{E}_{\text {cap }}} \\
\boldsymbol{F}_{\text {buoy }}=-m_{\mathrm{D}} \frac{\rho_{\text {water }}-\rho_{\text {air }}}{\rho_{\text {water }}} g \boldsymbol{u}_{y} \\
\boldsymbol{F}_{\text {Drag }}=-\frac{C_{\mathrm{D}} \pi \rho_{\text {air }} U_{\mathrm{D}}^{2} A^{2}}{2} \frac{\boldsymbol{U}_{\mathrm{D}}(t)}{\left\|\boldsymbol{U}_{\mathrm{D}}(t)\right\|} \\
\boldsymbol{F}_{\boldsymbol{E}_{\text {cap }}}=Q E_{\text {cap }} \boldsymbol{u}_{x},
\end{array}\right.
$$

with $\boldsymbol{u}_{\mathrm{D}}$ the instantaneous droplet velocity vector at the computational time $t, \rho_{\text {air }}$ and $\rho_{\text {water }}$ the air and water densities, $g$ the acceleration of gravity, $m_{\mathrm{D}}$ the droplet mass, $Q$ the droplet charge, $C_{\mathrm{D}}$ the drag coefficient, and $\boldsymbol{u}_{x}$ and $\boldsymbol{u}_{y}$ the unit vectors in the cartesian coordinate system visible in Fig. B2 (Left).

By projecting on the corresponding axis, the system of Eq. (B2) is obtained to solve

$$
\left\{\begin{array}{l}
m_{\mathrm{D}} \frac{\mathrm{d} U_{\mathrm{D}, x}(t)}{\mathrm{d} t}=Q E_{\mathrm{cap}}-\frac{C_{\mathrm{D}, x} \pi \rho_{\mathrm{air}} U_{\mathrm{D}, x}^{2} A^{2}}{2} \\
m_{\mathrm{D}} \frac{\mathrm{d} U_{\mathrm{D}, y}(t)}{\mathrm{d} t}=-m_{\mathrm{D}} \frac{\rho_{\text {water }}-\rho_{\text {air }}}{\rho_{\text {water }}} g-\frac{C_{\mathrm{D}, y} \pi \rho_{\mathrm{air}} U_{\mathrm{D}, y}^{2} A^{2}}{2},
\end{array}\right.
$$


where $C_{\mathrm{D}, x}$ and $C_{\mathrm{D}, y}$ are the drag coefficient projections depending on the Reynolds number projections $R e_{x}$ and $R e_{y}$ in the cartesian coordinate system. Since $R e_{x} \ll 1$ and $R e_{y}<2$ in the study, the drag coefficient projections are calculated from the analytical expression given by Hinds (2012) and summarised in Eq. (B3):

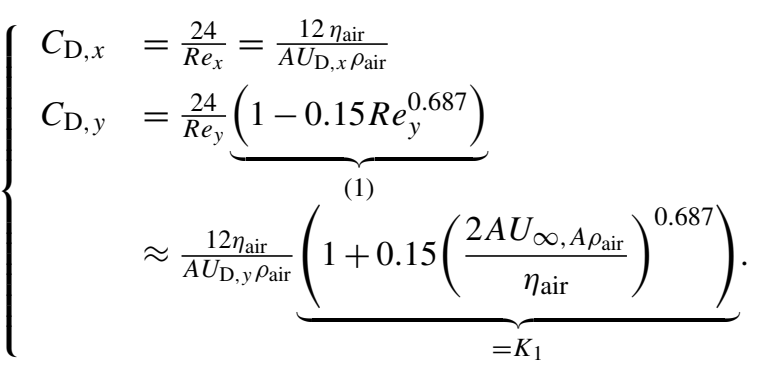

Note that the term (1) in Eq. (B3) is assumed to be constant to simplify the resolution of Eq. (B1) - giving second-order differential equations. This assumption is justified since $R e_{y}$ is close to the unity and then $C_{T, y}=\frac{24}{R e_{y}}$ remains suitable. The equation system to solve becomes (Eq. B4)

$$
\left\{\begin{array}{l}
m_{\mathrm{D}} \frac{\mathrm{d} U_{\mathrm{D}, x}(t)}{\mathrm{d} t}=\mathrm{QE}_{\text {cap }}-\overbrace{6 \pi A \eta_{\text {air }}}^{=K_{2}} U_{\mathrm{D}, x} \\
m_{\mathrm{D}} \frac{\mathrm{d} U_{\mathrm{D}, y}(t)}{\mathrm{d} t}=-m_{\mathrm{D}} \frac{\rho_{\text {water }}-\rho_{\text {air }}}{\rho_{\text {water }}} g-\underbrace{6 \pi A \eta_{\text {air }} K_{1}}_{=K_{3}} U_{\mathrm{D}, y} .
\end{array}\right.
$$

After two consecutive integrations with the initial conditions $-U_{\mathrm{D}, x}(t=0)=U_{D_{0}, x}, \quad U_{\mathrm{D}, y}(t=0)=U_{\infty, A}$, $\left(x_{\mathrm{D}}(t=0) y_{\mathrm{D}}(t=0)\right)=\left(x_{D_{0}} y_{D_{0}}\right)$, the analytical equations of the horizontal and vertical droplet positions, respectively referred to as $x_{\text {th }}$ and $y_{\text {th }}$, are given in Eq. (B5):

$$
\left\{\begin{aligned}
x_{\text {th }}(t)= & \frac{Q E_{\text {cap }}}{K_{2}} t+\frac{m_{\mathrm{D}}}{K_{2}}\left(U_{D_{0}, x}-\frac{Q E_{\text {cap }}}{K_{2}}\right)\left[1-e^{-\frac{K_{2}}{m_{\mathrm{D}}} t}\right]+x_{D_{0}} \\
y_{\text {th }}(t)= & -\frac{m_{\mathrm{D}}\left(\rho_{\text {water }}-\rho_{\text {air }}\right)}{K_{3} \rho_{\text {water }}} g t \\
& +\frac{m_{\mathrm{D}}}{K_{3}}\left(U_{\infty, A}+\frac{m_{\mathrm{D}}\left(\rho_{\text {water }}-\rho_{\text {air }}\right)}{K_{3} \rho_{\text {water }}} g\right)\left[1-e^{-\frac{K_{3}}{m_{\mathrm{D}}} t}\right]+y_{D_{0}},
\end{aligned}\right.
$$

where $E_{\text {cap }}=-\operatorname{grad}(V)=-\frac{V_{\text {cap }}}{0,01} \mathrm{~V} \mathrm{~m}^{-1}$.

As presented in Fig. B2 (Left), for every pair of pictures, the droplet charge $(Q)$ is then evaluated by looking for the theoretical droplet trajectory from Eq. (B5), which fits the best with the observed droplet positions. In the given example (Fig. B2, Left), the fitted theoretical trajectory - for $V_{\text {ind }}=-32.25 \mathrm{~V}, V_{\text {cap }}=-629.5 \mathrm{~V}, A=49.5 \mu \mathrm{m}$ and the air temperature $T_{\text {air }}=292.55 \mathrm{~K}$ - illustrated by the red line is obtained for a droplet charge $(Q)$ of $+9.10 \times 10^{4}|e|$. Finally, this method is applied for the 200 picture pairs to get the mean droplet charge value - visible in Fig. B2 (Right). Note that the standard deviation of the $200 Q$ values gives the error bars in Fig. 6. 
(a)
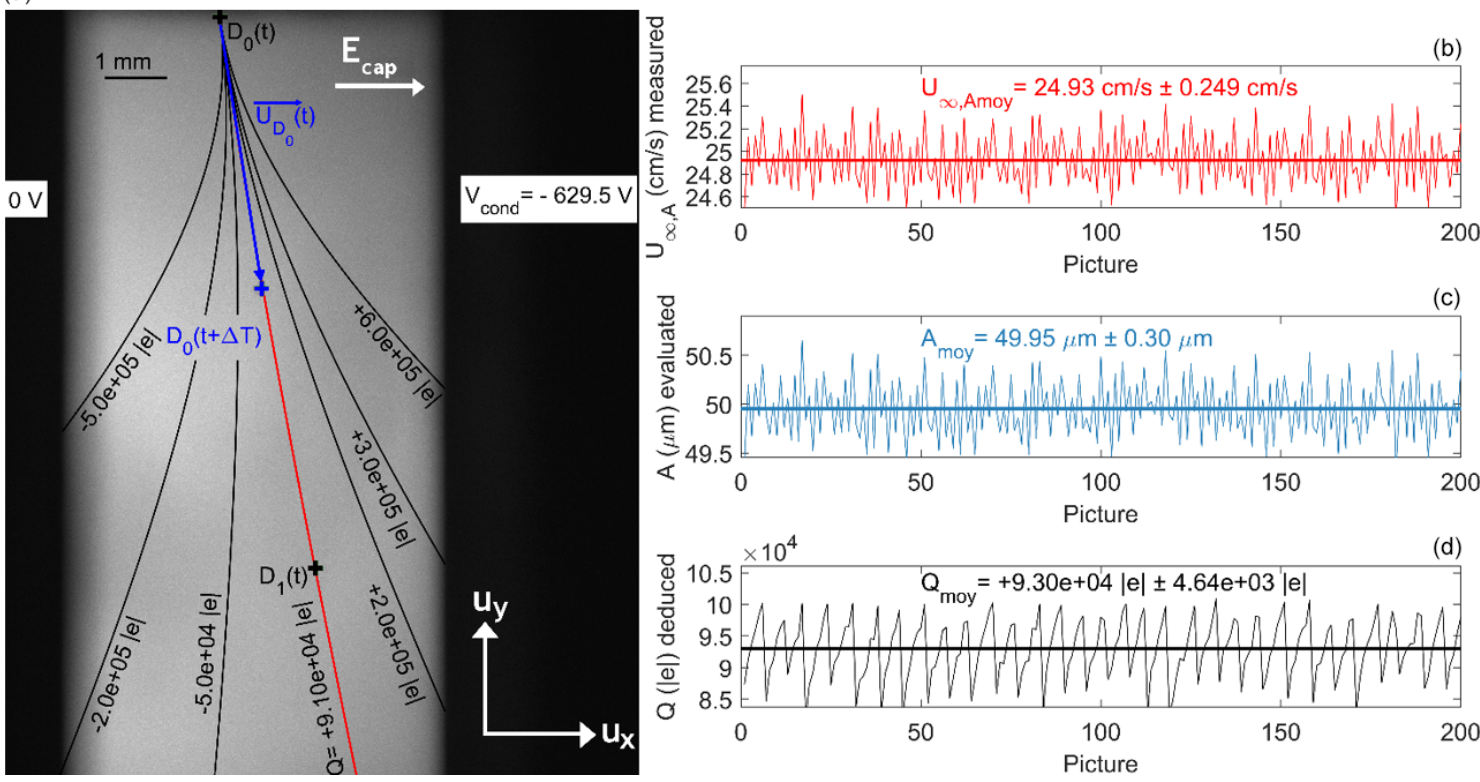

(b)
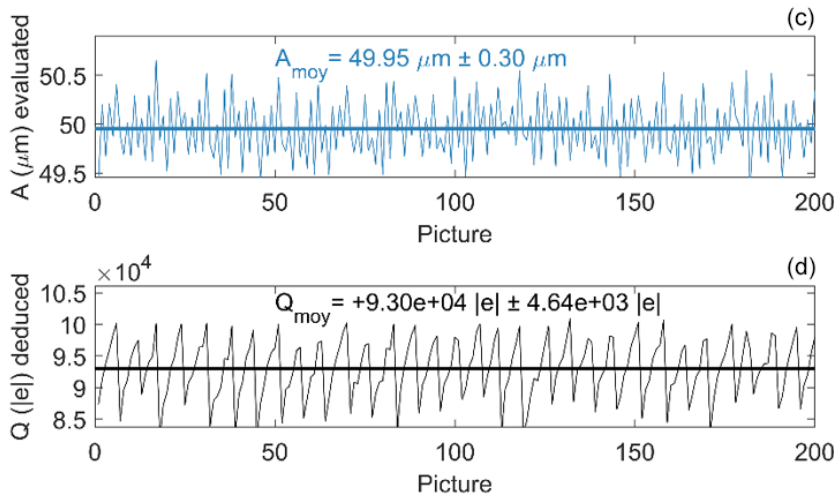

Figure B2. (a) Determination of the theoretical droplet trajectory which fits the best with the observed droplet positions - red line - and deduction of the droplet charge $(Q)$. In this example, $V_{\text {ind }}=-32.25 \mathrm{~V}, V_{\text {cap }}=-629.5 \mathrm{~V}, A=49.5 \mu \mathrm{m}$ and the air temperature $T_{\text {air }}=292.55 \mathrm{~K}$. (b) Terminal velocity measurement, (c) droplet radius evaluation by reversing the Beard (1976) model and (d) droplet charge deduction for a series of 200 pictures pairs. Mean and standard deviations for the corresponding parameters are presented. 


\section{B3 Validation}

The method presented in the previous section is possible as long as the droplet has reached its terminal velocity. As mentioned in Dépée et al. (2021) and visible in Fig. 8 (Left) of the same paper, droplets are generated at a velocity larger than their terminal velocity. It has been found that a distance between the droplet generator and the capacitor of $15 \mathrm{~cm}$ was large enough to allow droplets to reach their terminal velocity. In the setup in Fig. B1, this requirement prevails.

An experiment was performed to ensure that reversing the Beard (1976) model was a suitable method to evaluate the droplet radius. For this purpose, the same droplet train was recorded in optical shadowgraphy with a camera zoom at the lowest and at the highest setting to respectively apply the Beard (1976) model inversion and the circle Hough transform. In all tests, a discrepancy of less than $2 \%$ was found between the two methods, giving overvaluations as well as undervaluations when comparing one to the other.

Also, the disturbance of the electric field at the capacitor ( $\left.E_{\text {cap }}\right)$ on the vertical droplet velocity was studied. $E_{\text {cap }}$ was then turned on and off to investigate the change in vertical droplet velocity. It was found that during tests, $E_{\text {cap }}$ reduced the vertical velocity up to $1.3 \%$. This situation was for a droplet charge $(Q)$ and a capacitor potential $\left(V_{\text {cap }}\right)$ both negative. Some other tests also showed that the droplet vertical velocity was increased up to $0.3 \%$, for a droplet charge and a capacitor potential of unlike sign. Since these two extreme cases respectively represent an undervaluation of less than $0.7 \%$ and an overestimation of less than $0.2 \%$ of the droplet radius - this effect was neglected.

Finally, two other validations can be formulated by examining Fig. 6. First, several capacitor potentials $\left(V_{\text {cap }}\right)$ were used in the tests - from -629.5 to $-477.4 \mathrm{~V}-$ giving the same charging relationship. The Faraday Cage is consequently reliable; there is no impact of the electric field ( $\left.E_{\text {cap }}\right)$ on the droplet charge. Secondly, in the four tests the droplet radius varies from 47.0 to $51.2 \mu \mathrm{m}$. Thus, the droplet charging system is independent of the droplet size and droplet evaporation. 
Code availability. No code was developed in the present article. The code used was described in Dépée et al. (2019), published in Journal of Aerosol Science, https://doi.org/10.1016/j.jaerosci.2019. 04.001 .

Data availability. All the underlying research data can be found in the present article.

Author contributions. This work relies on the experimental work of $\mathrm{AD}$, with a methodology and a conceptualization made in collaboration with PL. Formal analysis was also performed by AD and PL. Numerical simulations were performed by AD and TG. The original article was written by AD under the supervision of PL, MM and AF.

Competing interests. The authors declare that they have no conflict of interest.

Acknowledgements. Authors sincerely thank Nicolas Jidenko for all the advice he provided on the development of the aerosol charger. Authors also thank François Gensdarmes for his support.

Financial support. This work was funded by the French Institute for Radiological Protection and Nuclear Safety (IRSN).

Review statement. This paper was edited by Joachim Curtius and reviewed by two anonymous referees.

\section{References}

Ardon-Dryer, K., Huang, Y.-W., and Cziczo, D. J.: Laboratory studies of collection efficiency of sub-micrometer aerosol particles by cloud droplets on a single-droplet basis, Atmos. Chem. Phys., 15, 9159-9171, https://doi.org/10.5194/acp-15-9159-2015, 2015.

Barlow, A. K. and Latham, J.: A laboratory study of the scavenging of sub-micron aerosol by charged raindrops, Q. J. Roy. Meteor. Soc., 109, 763-770, 1983.

Beard, K. V.: Experimental and numerical collision efficiencies for submicron particles scavenged by small raindrops, J. Atmos. Sci., 31, 1595-1603, 1974.

Beard, K. V.: Terminal velocity and shape of cloud and precipitation drops aloft, J. Atmos. Sci., 33, 851-864, 1976.

Byrne, M. A. and Jennings, S. G.: Scavenging of sub-micrometre aerosol particles by water drops, Atmos. Environ. A-Gen., 27, 2099-2105, 1993.

Chate, D. M. and Pranesha, T. S.: Field studies of scavenging of aerosols by rain events, J. Aerosol Sci., 35, 695-706, 2004.

Cherrier, G., Belut, E., Gerardin, F., Tanière, A., and Rimbert, N.: Aerosol particles scavenging by a droplet: Microphysical modeling in the Greenfield gap, Atmos. Environ., 166, 519-530, 2017.
Clement, C. F. and Harrison, R. G.: The charging of radioactive aerosols, J. Aerosol Sci., 23, 481-504, 1992.

Davenport, H. M. and Peters, L. K.: Field studies of atmospheric particulate concentration changes during precipitation, Atmos. Environ., 12, 997-1008, 1978.

Dépée, A., Lemaitre, P., Gelain, T., Mathieu, A., Monier, M., and Flossmann, A.: Theoretical study of aerosol particle electroscavenging by clouds, J. Aerosol Sci., 135, 1-20, 2019.

Dépée, A., Lemaitre, P., Gelain, T., Monier, M., and Flossmann, A.: Laboratory study of the collection efficiency of submicron aerosol particles by cloud droplets - Part I: Influence of relative humidity, Atmos. Chem. Phys., 21, 6945-6962, https://doi.org/10.5194/acp-21-6945-2021, 2021.

Depuydt, G.: Etude expérimentale in situ du potentiel de lessivage de l'aérosol atmosphérique par les précipitations (Doctoral dissertation), Institut National Polytechnique de Toulouse, available at: http://ethesis.inp-toulouse.fr/archive/00002550/, 2013.

Dockery, D. W., Schwartz, J., and Spengler, J. D.: Air pollution and daily mortality: associations with particulates and acid aerosols, Environ. Res., 59, 362-373, 1992.

Flossmann, A. I.: Interaction of aerosol particles and clouds, J. Atmos. Sci., 55, 879-887, 1998.

Flossmann, A. I., Hall, W. D., and Pruppacher, H. R.: A theoretical study of the wet removal of atmospheric pollutants, Part I: The redistribution of aerosol particles captured through nucleation and impaction scavenging by growing cloud drops, J. Atmos. Sci., 42, 583-606, 1985.

Greenfield, S. M.: Rain scavenging of radioactive particulate matter from the atmosphere, J. Meteorol., 14, 115-125, 1957.

Grover, S. N. and Beard, K. V.: A numerical determination of the efficiency with which electrically charged cloud drops and small raindrops collide with electrically charged spherical particles of various densities, J. Atmos. Sci., 32, 2156-2165, 1975.

Grover, S. N., Pruppacher, H. R., and Hamielec, A. E.: A numerical determination of the efficiency with which spherical aerosol particles collide with spherical water drops due to inertial impaction and phoretic and electrical forces, J. Atmos. Sci., 34, 1655-1663, 1977.

Hinds, W. C.: Aerosol technology: properties, behavior, and measurement of airborne particles, John Wiley \& Sons, New York, Chichester, Weinheim, Bribane, Singapore, Toronto, 483 pp., 2012.

Jackson, J. D.: Classical electrodynamics, 3rd edition, Wiley \& Sons, New York, London, Sydney, 808, 1999.

Jaenicke, R.: Chapter 1: Tropospheric aerosols, Aerosolcloud-climate interactions, in: International Geophysics, Vol. 54, edited by: Hobbs, P. Academic Press, 1-31, https://doi.org/10.1016/S0074-6142(08)60210-7, 1993.

Jaworek, A., Adamiak, K., Balachandran, W., Krupa, A., Castle, P., and Machowski, W.: Numerical simulation of scavenging of small particles by charged droplets, Aerosol Sci. Tech., 36, 913 924, 2002.

Kerker, M. and Hampl, V.: Scavenging of Aerosol Particles by a Failing Water Drop and Calculation of Washout Coefficients, J. Atmos. Sci., 31, 1368-1376, 1974.

Kraemer, H. F. and Johnstone, H. F.: Collection of aerosol particles in presence of electrostatic fields, Ind. Eng. Chem., 47, 24262434. 
Laakso, L., Grönholm, T., Rannik, Ü., Kosmale, M., Fiedler, V., Vehkamäki, H., and Kulmala, M.: Ultrafine particle scavenging coefficients calculated from 6 years field measurements, Atmos. Environ., 37, 3605-3613, 2003.

Ladino, L., Stetzer, O., Hattendorf, B., Günther, D., Croft, B., and Lohmann, U.: Experimental study of collection efficiencies between submicron aerosols and cloud droplets, J. Atmos. Sci., 68, 1853-1864, 2011.

Laguionie, P., Roupsard, P., Maro, D., Solier, L., Rozet, M., Hébert, D., and Connan, O.: Simultaneous quantification of the contributions of dry, washout and rainout deposition to the total deposition of particle-bound $7 \mathrm{Be}$ and $210 \mathrm{~Pb}$ on an urban catchment area on a monthly scale, J. Aerosol Sci., 77, 67-84, 2014.

Lai, K. Y., Dayan, N., and Kerker, M.: Scavenging of aerosol particles by a falling water drop, J. Atmos. Sci., 35, 674-682, 1978.

Lemaitre, P., Querel, A., Monier, M., Menard, T., Porcheron, E., and Flossmann, A. I.: Experimental evidence of the rear capture of aerosol particles by raindrops, Atmos. Chem. Phys., 17, 41594176, https://doi.org/10.5194/acp-17-4159-2017, 2017.

Lemaitre, P., Sow, M., Quérel, A., Dépée, A., Monier, M., Menard, T., and Flossmann, A. I.: Contribution of Phoretic and Electrostatic Effects to the Collection Efficiency of Submicron Aerosol Particles by Raindrops, Atmosphere, 11, 1-19, 1028TS29, https://doi.org/10.3390/atmos11101028, 2020.

Lira, I.: Evaluating the measurement uncertainty: fundamentals and practical guidance, in: institute of physics, series in measurement science and technology, Institute of Physics Publishing, Bristol and Philadelphia, 251, https://doi.org/10.1119/1.1522703, 2002.

Pauthenier, M. and Moreau-Hanot, M.: La charge des particules sphériques dans un champ ionisé, J. Phys. Radium, 3, 590-613, 1932.

Pranesha, T. S. and Kamra, A. K.: Scavenging of aerosol particles by large water drops: 1. Neutral case, J. Geophys. Res.-Atmos., 101, 23373-23380, 1996.

Pruppacher, H. R. and Klett, J. D.: Microphysics of Clouds and Precipitation, in Atmospheric and oceanographic Sciences Library, Kluwer Academic Press, Dordrecht/Boston/London, 954 pp., 1997.

Quérel, A., Lemaitre, P., Monier, M., Porcheron, E., Flossmann, A. I., and Hervo, M.: An experiment to measure raindrop collection efficiencies: influence of rear capture, Atmos. Meas. Tech., 7, 1321-1330, https://doi.org/10.5194/amt-7-1321-2014, 2014.

Reischl, G. P. W. W., John, W., and Devor, W.: Uniform electrical charging of monodisperse aerosols, J. Aerosol Sci., 8, 55-65, 1977.

Santachiara, G., Prodi, F., and Belosi, F.: A review of termo-and diffusio-phoresis in the atmospheric aerosol scavenging process, Part 1: Drop scavenging, 2, 148-158, https://doi.org/10.4236/acs.2012.22016, 2012.
Slinn, W. G. N.: Precipitation scavenging: some problems, approximate solutions and suggestions for future research No. BNWLSA-5062, Battelle Pacific Northwest Labs., Richland, Wash, USA, 1974.

Slinn, W. G. N. and Hales, J. M.: A reevaluation of the role of thermophoresis as a mechanism of in-and below-cloud scavenging, J. Atmos. Sci., 28, 1465-1471, 1971.

Takahashi, T.: Measurement of electric charge of cloud droplets, drizzle, and raindrops, Rev. Geophys., 11, 903-924, 1973.

Tinsley, B. A. and Zhou, L.: Parameterization of aerosol scavenging due to atmospheric ionization, J. Geophys. Res.-Atmos., 120, 8389-8410, 2015.

Tinsley, B. A., Rohrbaugh, R. P., Hei, M., and Beard, K. V.: Effects of image charges on the scavenging of aerosol particles by cloud droplets and on droplet charging and possible ice nucleation processes, J. Atmos. Sci., 57, 2118-2134, 2000.

Tinsley, B. A., Zhou, L., and Plemmons, A.: Changes in scavenging of particles by droplets due to weak electrification in clouds, Atmos. Res., 79, 266-295, 2006.

Twomey, S.: Pollution and the planetary albedo, Atmos. Environ., 8, 1251-1256, 1974.

Unger, L.: Charge d'aérosols par décharge électrique pour la filtration d'effluents particulaires. Orsay: PhD thesis of Université Paris Sud., 2001.

Unger, L., Boulaud, D., and Borra, J. P.: Unipolar field charging of particles by electrical discharge: effect of particle shape, J. Aerosol Sci., 35, 965-979, 2004.

Vohl, O., Mitra, S. K., Wurzler, S., Diehl, K., and Pruppacher, H. R.: Collision efficiencies empirically determined from laboratory investigations of collisional growth of small raindrops in a laminar flow field, Atmos. Res., 85, 120-125, 2007.

Volken, M. and Schumann, T.: A critical review of below-cloud aerosol scavenging results on Mt. Rigi, Water Air Soil Poll., 68, 15-28, 1993.

Wang, H. C., Leong, K. H., Stukel, J. J., and Hopke, P. K.: Collection of hydrophilic and hydrophobic charged submicron particles by charged water droplets, J. Aerosol Sci., 14, 703-712, 1983.

Wang, P. K. and Pruppacher, H. R.: An experimental determination of the efficiency with which aerosol particles are collected by water drops in subsaturated air, J. Atmos. Sci., 34, 1664-1669, 1977.

Wang, P. K., Grover, S. N., and Pruppacher, H. R.: On the effect of electric charges on the scavenging of aerosol particles by clouds and small raindrops, J. Atmos. Sci., 35, 1735-1743, 1978.

Young, K. C.: The role of contact nucleation in ice phase initiation in clouds, J. Atmos. Sci., 31, 768-776, 1974. 